Article

\title{
Emission Characteristics for a Homogeneous Charged Compression Ignition Diesel Engine with Exhaust Gas Recirculation Using Split Injection Methodology
}

\author{
Changhee Lee ${ }^{1, *}$ (D), Jaewoo Chung ${ }^{2}$ and Kihyung Lee ${ }^{3, *}$ \\ 1 Department of Mechanical and Automotive Engineering, Songwon University, Songarm-ro, \\ Gwangju-ci 61756, Korea \\ 2 Gas Engine System R\&D Center-Green Car Power System R\&D Division, KATECH, \\ Chunan-si 330-912, Korea; leemech@hanyang.ac.kr \\ 3 Department of Mechanical Engineering, Hanyang University, Kyounggi-do 15588, Korea \\ * Correspondence: leemech@songwon.ac.kr (C.L.); hylee@hanyang.ac.kr (K.L.); \\ Tel.: +82-62-360-5916 (C.L.); +82-31-400-5251 (K.L.)
}

Received: 28 October 2017; Accepted: 13 December 2017; Published: 15 December 2017

\begin{abstract}
Due to the serious issues caused by air pollution and global warming, emission regulations are becoming stricter. New technologies that reduce $\mathrm{NO}_{\mathrm{x}}$ and $\mathrm{PM}$ emissions are needed. To cope with these social exhaust gas regulation demands, many advanced countries are striving to develop eco-friendly vehicles in order to respond to stricter emissions regulations. The homogeneous charged compression ignition engine (HCCI) incorporates a multi-stage combustion engine with multiple combustion modes, catalyst, direct fuel injection and partial mixing combustion. In this study, the HCCI combustion was applied to analyze and review the results of engines applying HCCI combustion without altering the conventional engine specifications. The optimization of exhaust gas recirculation (EGR) and compression ratio changes provides an optimal fuel economy. In this study, potential for optimum economy within the range of IMEP $0.8 \mathrm{MPa}$ has been evaluated.
\end{abstract}

Keywords: Homogeneous Charged Compression Ignition (HCCI); Exhaust Gas Recirculation (EGR); multiple injections; compression ratio; intake pressure; Indicated Mean Effective Pressure (IMEP); Bottom Top Dead Center (BTDC); After Top Dead Center (ATDC)

\section{Introduction}

Due to the severity of air pollution caused by global automobile emissions, exhaust air emissions are being intensified. Future regulations are expected to become stronger. Therefore, a new concept of combustion technology is urgently needed to achieve reductions in $\mathrm{NO}_{\mathrm{x}}$ and $\mathrm{PM}$ emissions at the combustion level. Based on this backdrop, the advanced countries are striving to develop eco-friendly cars for environment-friendly cars. At the center of the new generation of engines for these next-generation vehicles is the homogeneous composite compression ignition (HCCI) combustion concept. The application is expanding the scope of multiple combustion modes, the application of catalyst applications, the use of direct fuel supply, and the incorporation of partial examples [1-8].

There are various similar concepts to the HCCI concept engine such as Active Thermos-atmosphere Combustion (ATAC) [9], Compression-Ignition Homogeneous Charge (CIHC) [10], Premixed Lean Diesel Engine Combustion (PCCI) [11,12], Controlled Auto-Ignition (CAI) [13-15] and Stratified Charged Compression Ignition (SCCI) [14-16]. The ATAC engine concept is applied most easily to two-stroke cycle gasoline engines. As stated above, the concepts of the CIHC, PCCI and HCCI engines involve a form of internal combustion at the point of auto-ignition with homogeneous mixed fuel and oxidizer. The application of CAI engines is mainly for reduction in fuel consumption and $\mathrm{NO}_{\mathrm{x}}$ 
emissions. Finally, SCCI engines have the potential to overcome many of these barriers: the stratified charged mixture improves emissions and combustion efficiency under operating conditions of partial load and a range of speeds and loads.

Maurya et al. [17] investigated the thermal efficiency and emissions in HCCI engines in accordance with different air-fuel ratios and intake air temperatures (120-150 Celsius). Kim et al. [18] have investigated experimentally and numerically the effect of the premixed ratio and supply conditions of premixed fuel in partial HCCI engines. Lu et al. [19] suggested new combustion modes such as HCCI, SCCI and Low Temperature Combustion (LTC) which of prominent characteristics are the use of lean fuel/air mixtures and their Exhaust Gas Recirculation (EGR) rate.

Charalambides [20] investigated the difference between the HCCI auto-ignition process and the pre-auto ignition propagation through homogeneous mixture or fuel stratification, internal exhaust gas recirculation (IEGR) and spark-assisted IEGR lean burn and visualized flame images using proper orthogonal decomposition (POD) for investigating the temporal and spatial repeatability of the auto ignition phenomenon.

In this paper, research on the development of dual system diesel engines is conducted. A two-stage injector is used to apply the HCCI combustion method without significant alteration of the engine data in both the combustion mode and the utility. In the case of the two-stage injector applied in this study, there is a tendency toward a partial combustion rather than a complete HCCI combustion. Further, the effects were analyzed by considering the effects of various combustion factors to improve combustion and exhaust performance. Appying forced charging, EGR and compression ratio change, fuel economy optimization and emission reduction in the IMEP 0.8 MPa range was investigated. As the 2nd stage injection system was applied to this study rather than the implementation of a complete HCCI combustion setup, there is a tendency towards partial premixed diesel combustion, and the effects of various combustion factors for improving combustion and exhaust performance are discussed.

\section{Experimental Methodology}

\subsection{Experimental Apparatus}

The engine used in this paper was a four-stroke single cylinder, direct injection engine. The engine specifications and a schematic diagram of the combustion and exhaust analysis in a HCCI engine are shown in Table 1 and Figure 1, respectively.

Table 1. Engine specifications.

\begin{tabular}{ccc}
\hline Engine Type & Single Cylinder & Base Engine \\
\hline Fuel type & Diesel & Diesel \\
Num. of cylinder-Bore $\times$ Stroke $(\mathrm{mm})$ & $1-102 \times 100$ & $4-102 \times 100$ \\
Stroke volume (cc/cylinder) & 817 & 817 \\
Number of intake valve (/cylinder) & 2 & 1 \\
Compression ratio & Variable (Max. 17.8) & 17.8 \\
Fuel supply system & Common-rail & Mechanical (VE pump) \\
Num. of nozzle hole $\times$ dia. $(\mathrm{mm})$ & $5 \times \varphi 0.168$ & $5 \times \varphi 0.26$ \\
Injection pressure (bar) & $<1350$ bar & 220 bar \\
Injection timing & Various & BTDC $13^{\circ}$ \\
Max. rpm/Max. pressure (bar) & $4000 / 120$ & $2300 / 100$ \\
Intake charging & Supercharging & W/O \\
Swirl & Variable $(\mathrm{SCV})$ & - \\
EGR & With & $\mathrm{W} / \mathrm{O}$ \\
Conrad/Crank radius $(\mathrm{mm})$ & $167 / 50$ & $167 / 50$ \\
\hline
\end{tabular}




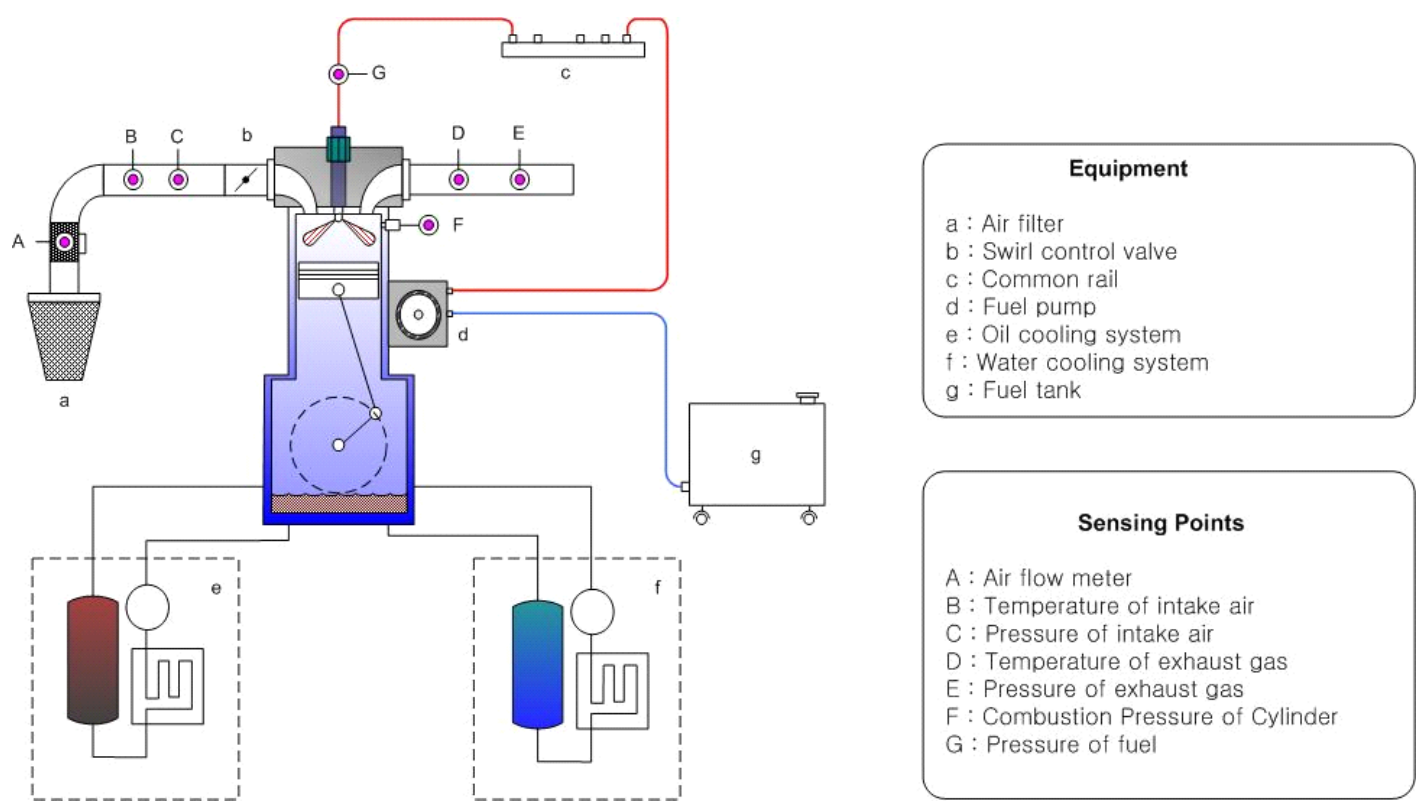

Figure 1. Experimental apparatus for analysis of the combustion and exhaust performance in a HCCI engine.

The fuel density and viscosity of the diesel fuel used in this research were $0.85 \mathrm{~g} / \mathrm{cm}^{3}$ at $15{ }^{\circ} \mathrm{C}$, and 1.9-4.1 cST@40 ${ }^{\circ} \mathrm{C}, \mathrm{mm}^{2} / \mathrm{s}$, respectively. The engine specifications that affect the HCCI combustion are the swirl ratio of the intake port, the configuration of the combustion chamber, the compression ratio and the fuel supply system of the $\mathrm{HCCI}$ system. As shown in Figure 1, the system includes an engine dynamometer, control panel, data acquisition system and sensors. The dynamo-meter system is an AC $126 \mathrm{~kW}$ manufactured by AVL (Graz, Austria). The pressure sensors used for measuring in-cylinder pressure were a model 6051 (piezo-electric type) and a model 4045A2 (resistance type), both from Kistler (Winterthur, Switzerland). A pressure signal was acquired at every 0.1 crank angle degree (CAD) using 7200/rev with a Kistler shaft encoder (this signal is used for crank angle reference). The heat release rate used pressure signal was calculated by a zero-dimensional combustion model according to the in-cylinder pressure of an average of 100 cycles for each operating point. The composition of the exhaust gas emissions $\left(\mathrm{CO}, \mathrm{HC}\right.$ and $\left.\mathrm{NO}_{\mathrm{x}}\right)$ were measured by a gas analyzer (MEXA 9100D, Horiba, Tokyo, Japan) and smoke opacity was measured by a smoke meter (AVL 415).

The variation of compression ratio is the method used for adjusting the height of the cylinder heat using a height plate. The EGR was adjusted through the opening and closing of the EGR valve in the connecting passage of the exhaust pipe and the intake pipe. When the EGR valve adjustment was not possible only with the increase in the EGR ratio, the EGR rate was adjusted by increasing the back pressure of the exhaust pipe. The measurement of EGR rate during the time of the experiments was calculated using the ratio of $\mathrm{CO}_{2}$ of the exhaust gas to $\mathrm{CO}_{2}$ of the intake pipe measured with the exhaust gas analyzer. For this Equation (1) was used. Supercharging was implemented in the experiments by applying an automobile supercharger.

$$
\operatorname{EGR}(\%)=\frac{\mathrm{CO}_{2}\left(\int\right)-\mathrm{CO}_{2(A m b)}}{\mathrm{CO}_{2(e x h)}-\mathrm{CO}_{2(A m b)}} \times 100
$$

\subsection{Determination of Experimental Conditions}

The basic combustion and emission characteristics using a 2-stage injection method were investigated and the factors to improve the combustion and emission performance were evaluated. Figure 2 shows the effects of fuel injection timing changes and variations on the combustion and 
exhaust emission characteristics. It indicates the schematic diagram for the qualitative characteristics in Figure 1. From the results of Figure 2a, as 1st injection timing in the HCCI mode is advanced, the $\mathrm{NO}_{\mathrm{x}}$ emissions were excellent compared to conventional combustion. The 2 nd injection timing had relatively less effect on the $\mathrm{NO}_{x}$ emissions. The smoke emissions, as shown in Figure $2 \mathrm{~b}$, have a significant impact on the injection timing of the 1st (early injection) and 2nd (late injection). As the 1st injection timing is advanced and 2nd injection is retarded from TDC, the smoke reduction characteristics get better. It is considered that the injection timing of the 1st injection has an effect on the reduction of $\mathrm{NO}_{\mathrm{x}}$ and smoke and the 2nd injection only has an effect on the reduction of the smoke.

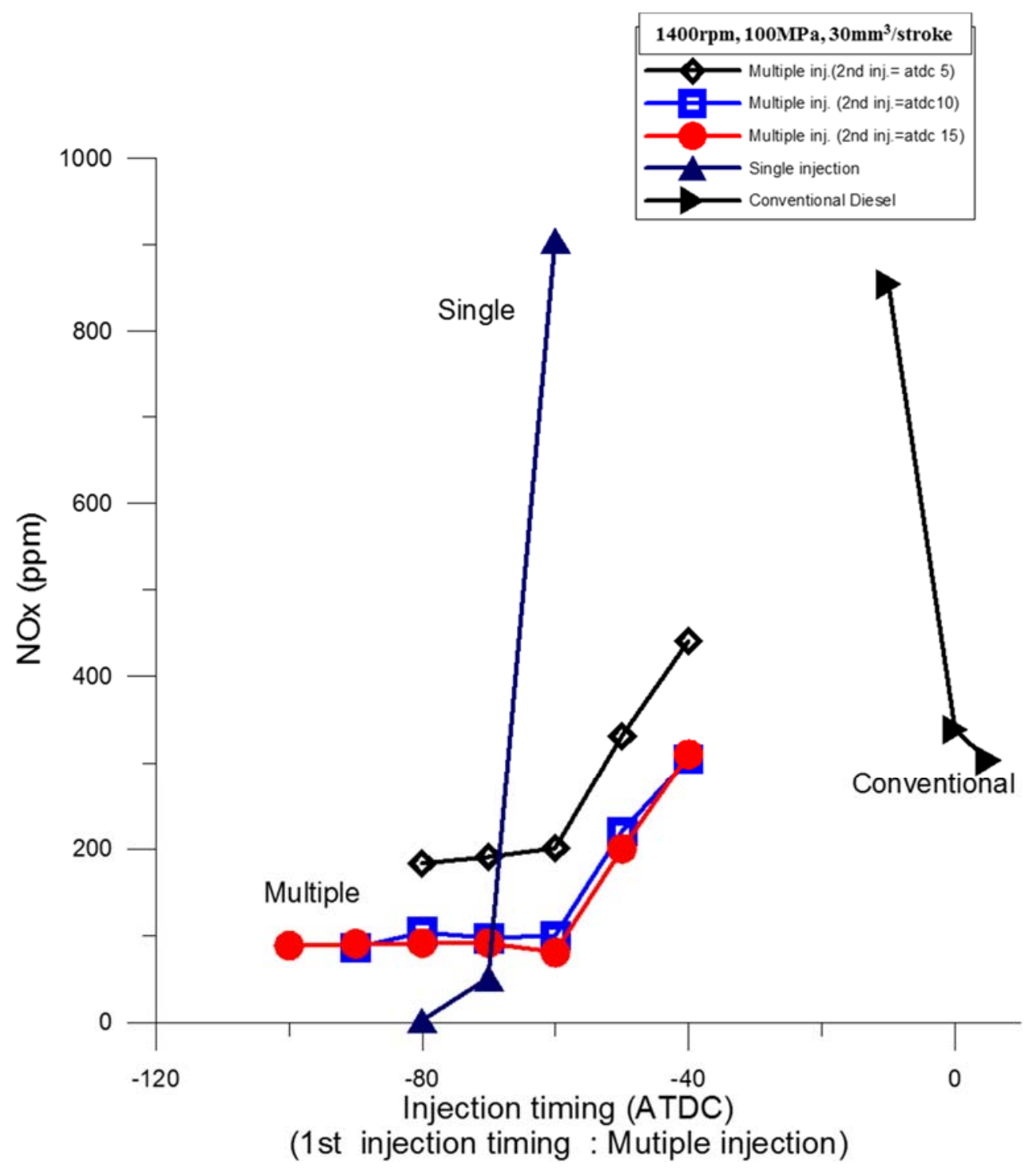

(a)

Figure 2. Cont. 


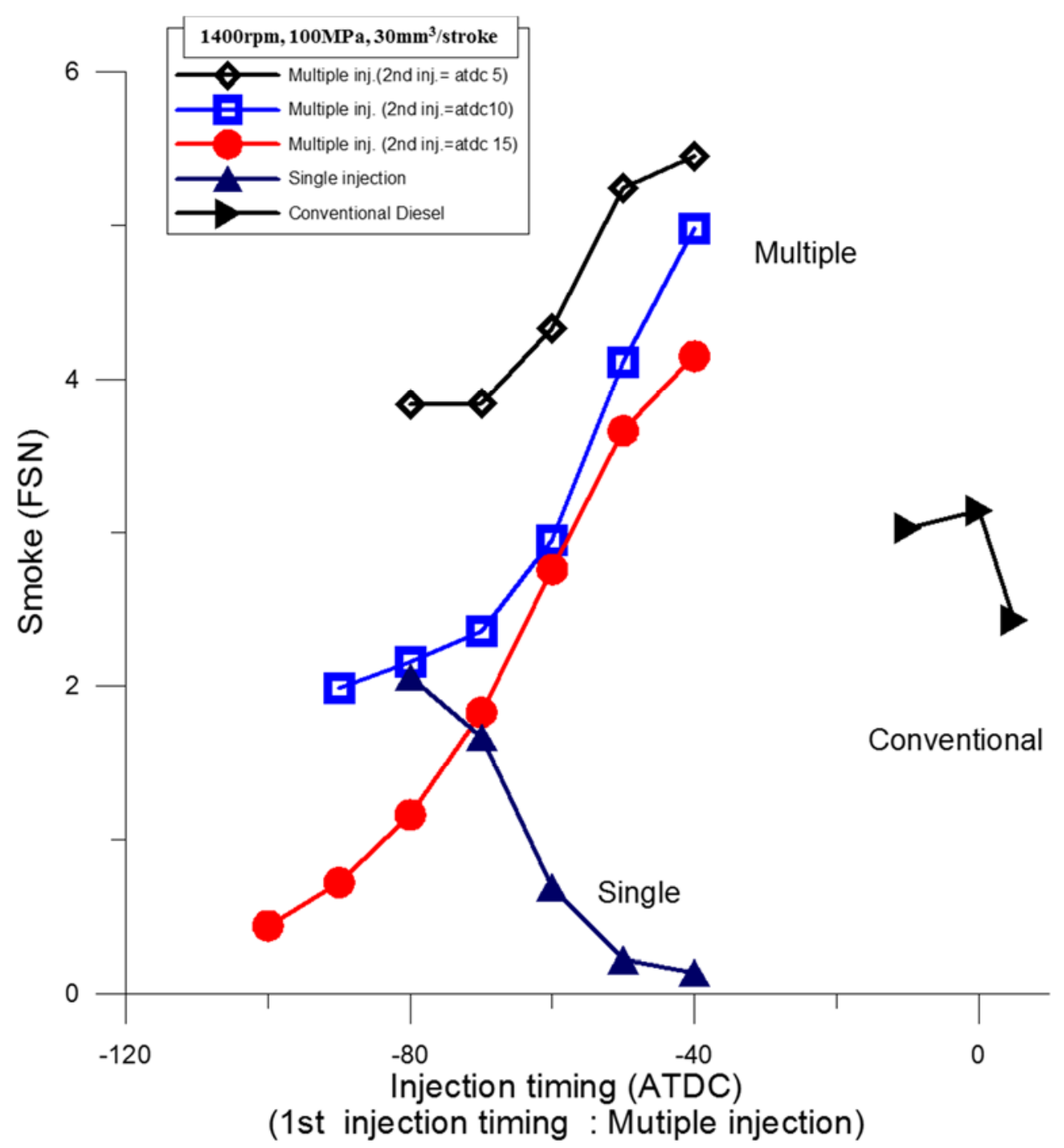

(b)

Figure 2. Emission performance of multiple injection diesel DI-HCCI combustion (1400 rpm, $30 \mathrm{~mm}^{3}$ /stroke). (a) $\mathrm{NO}_{x}$; (b) Smoke.

As shown in the previous paper [21], the experimental results indicate that when the injection timing of the first stage is advanced or the injection timing of the second stage is delayed, the exhaust performance such as $\mathrm{NO}_{\mathrm{x}}$ and smoke emissions is excellent, but the IMEP performance shows a deterioration. As the amount of fuel injection rate becomes large, the power loss becomes larger. Considering such injection timing, exhaust gas and IMEP characteristics, it was judged that BTDC 80-60 degree was suitable for the first injection stage and ATDC 10 degree was suitable for the second injection stage. From the abovementioned results, considering the way to improve the performance, the main factor of the performance improvement method is to delay the ignition of the first injected fuel to burn close to the TDC; the ignition of the second injected fuel is also retarded as much as possible and the premixing rate is increased. The technology for realizing these contents is shown in Figure 3. The technical solution for realizing the research is shown in Figure 4. The experimental conditions used in this paper are illustrated in Figure 5. 


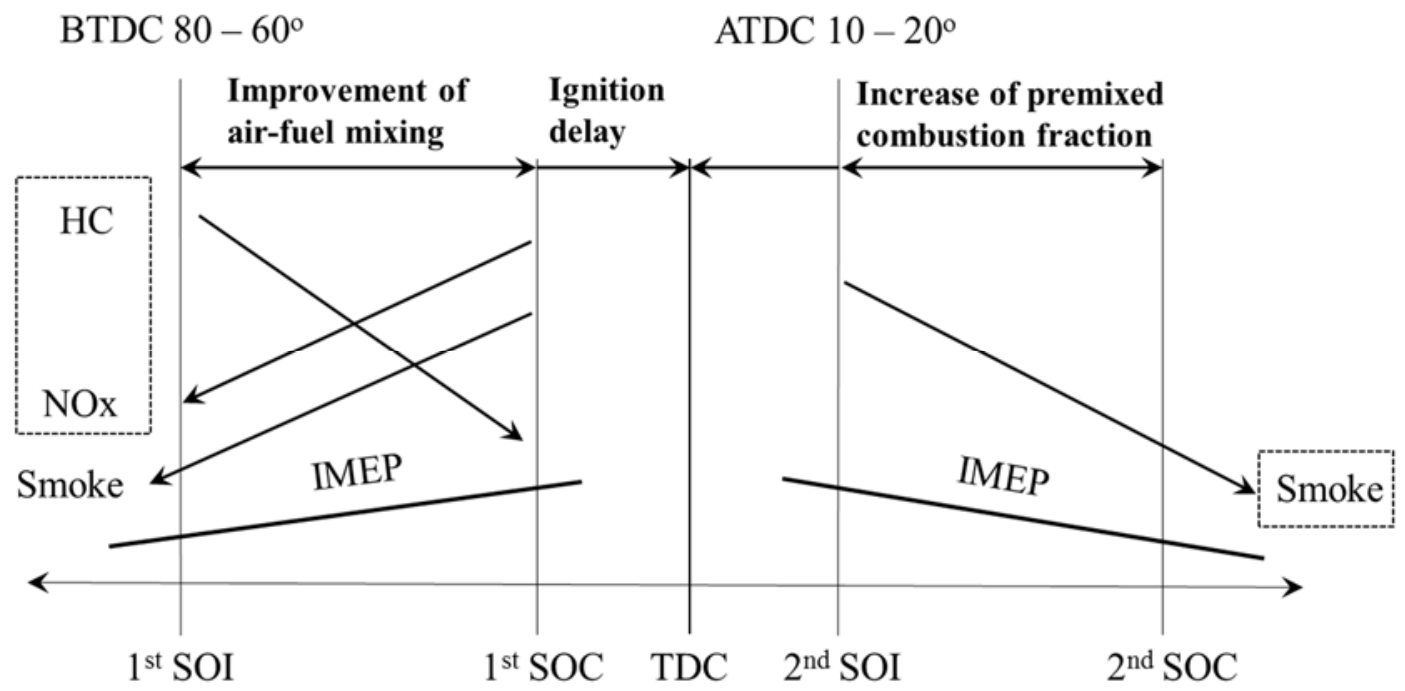

Figure 3. Effect of injection timing of multiple injection method (SOI: Start of Injection, SOC: Start of Combustion).

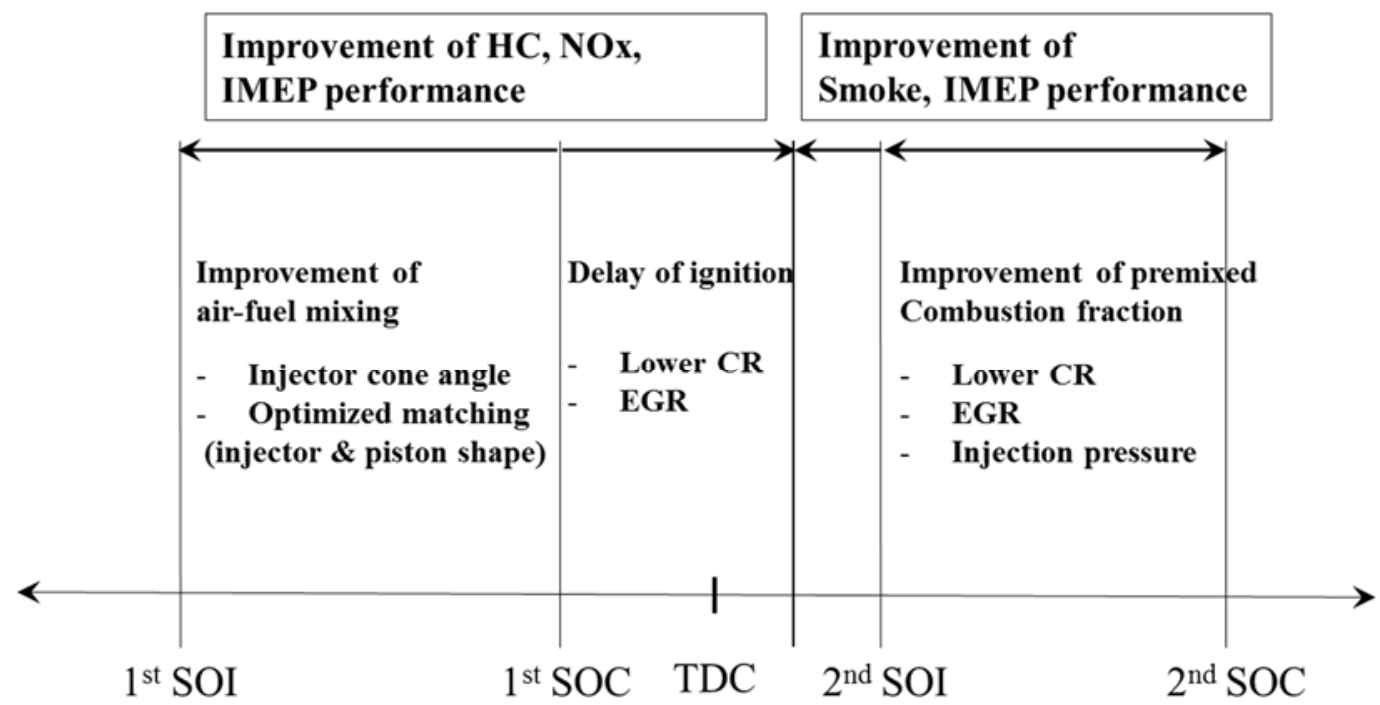

Figure 4. Engine performance improvement of the multiple injection method.

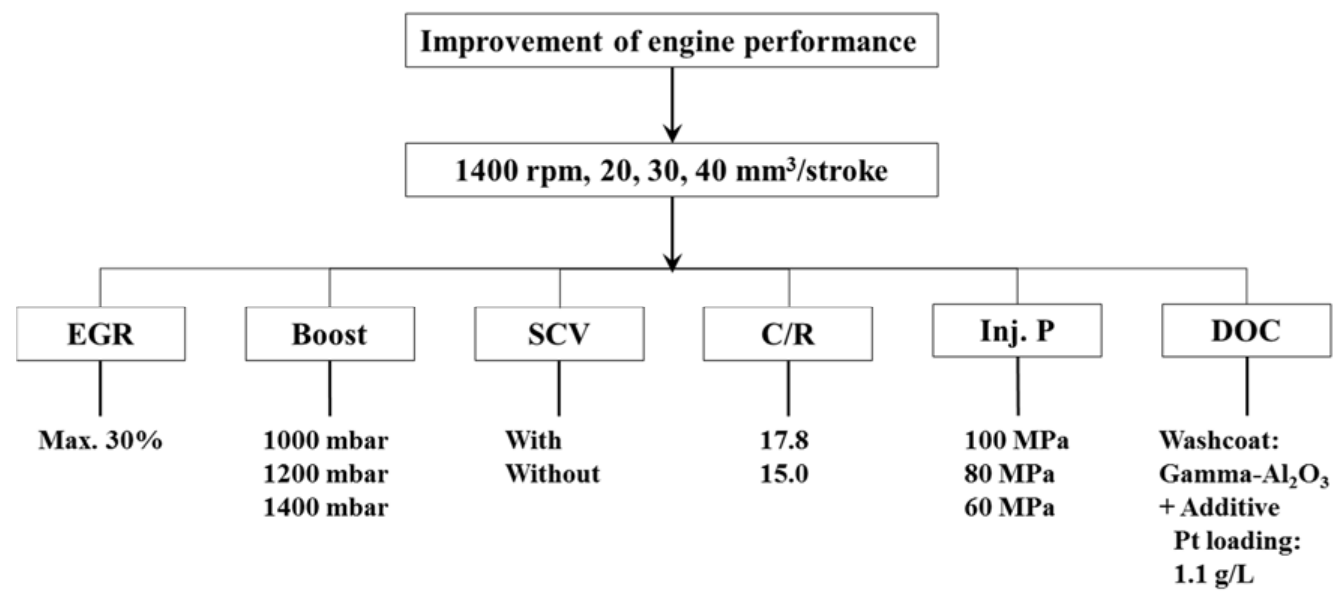

Figure 5. Test parameters and conditions. 


\section{Results and Discussion}

\subsection{Consideration of Emission Characteristics and Combustion Control Factors for the Various Air-Fuel Ratios}

The combustion control factor applied to the HCCI engine has an effect on its parameters. It is necessary to understand the basic concepts of combustion control such as the operating conditions, and fuel amounts (loads). At first, the air-fuel ratios for investigating the characteristics of $\mathrm{NO}_{\mathrm{x}}$ and smoke were applied to set the range of air-fuel ratio (fuel amounts) for each factor. Figure 6 shows the characteristics of $\mathrm{NO}_{\mathrm{x}}$ and smoke in accordance with changing air-fuel ratio when the injection amount and supercharging rate conditions are 20,30, $40 \mathrm{~mm}^{3}$ /stroke and 100, 1200, $1400 \mathrm{mbar}$, respectively. As the multi-injection method $\mathrm{HCCI}$ technology was applied, the $\mathrm{NO}_{\mathrm{x}}$ emissions are reduced to about $30 \%$ more than the base engine (conventional engine) as shown in Figure 6a. These characteristics at the split injection mode were enhanced to the premixed performance or the power performance was excellent in the performance of $\mathrm{NO}_{x}$ reduction. However, the smoke characteristics, as shown in Figure $6 b$, were worse than in the base engine in the case of TDC injection. For the multi-injection case, the injection timing improved the premixed performance, and it could be confirmed that the smoke was very low.

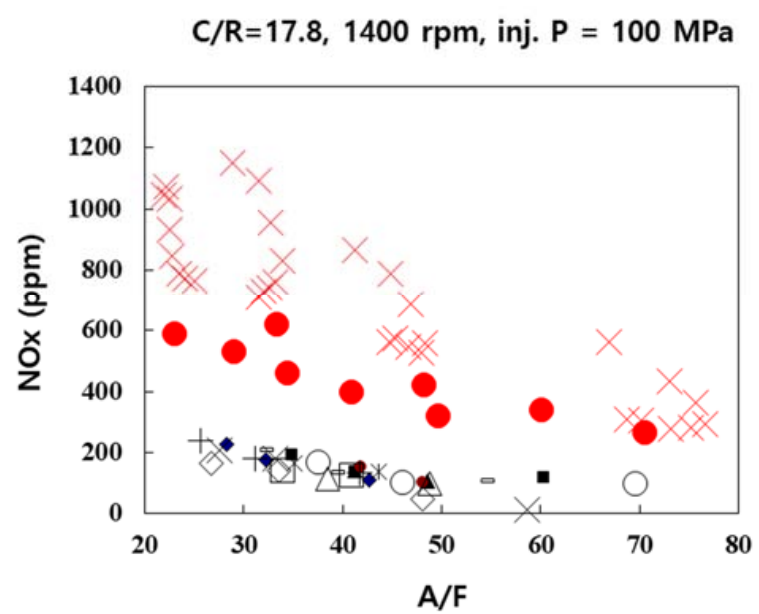

(a)

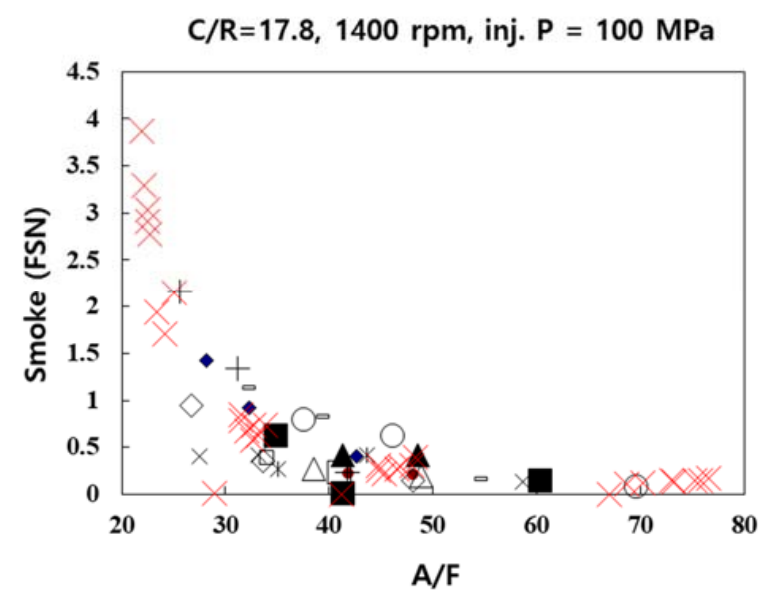

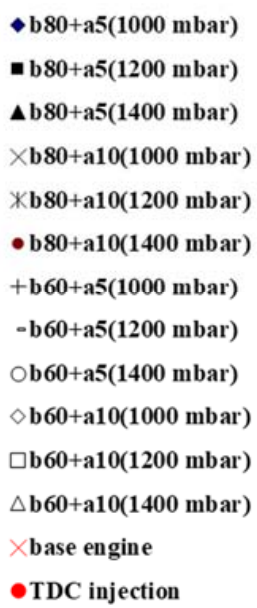

-TDC injection
- b80+a5(1000 mbar)

- b80+a5(1200 mbar)

$\triangle$ b80+a5(1400 mbar)

$\times$ b80+a10(1000 mbar)

*b80+a10(1200 mbar)

- b80+a10(1400 mbar)

+b60+a5(1000 mbar)

-b60+a5(1200 mbar)

○ b0+a5(1400 mbar)

$\diamond$ b6+a10(1000 mbar)

$\square$ b60+a10(1200 mbar)

$\triangle$ b60+a10(1400 mbar)

$\times$ base engine

(b)

Figure 6. Characteristics on the emissions of $\mathrm{NO}_{\mathrm{x}}$ and smoke in accordance with the air-fuel ratio (multiple injection mode). (a) $\mathrm{NO}_{x}$ characteristics according to the air-fuel ratio; (b) smoke characteristics according to the air-fuel ratio. 
As a result, the characteristics of the air-fuel ratio at the predetermined injection amount and the injection timing confirmed that the boundary conditions selected for application of combustion parameters for the various combustion and improved exhaust should be set before and after the $\mathrm{A} / \mathrm{F}=30$.

\subsection{Effect on the Swirl Control Valve}

One of the big problems with current HCCI diesel engine designs is poor mixing of the injected fuel and air and a lack of air mixing time. These problems could be improved through improved mixing performance by strengthening the intake swirl flow. The role of such a swirl could be evaluated differently depending on the operating range of engine.

The application of a swirl control valve (SCV) has been considered for use in a relatively lean region, since it tends to reduce the intake flow amount by blocking a portion of the intake port. Figure 7 shows the IMEP, A/F and emission characteristics when a SCV is applied and the experimental conditions were compression ratio 17.8, $1400 \mathrm{rpm}$ and injection amount $20 \mathrm{~mm}^{3} /$ stroke, respectively.

As the $\mathrm{SCV}$ is installed at the intake port, from the power performance $(0.35 \mathrm{MPa})$ and the air-fuel ratio (about $\mathrm{A} / \mathrm{F}=45$ ) it could be seen that there was a loss of IMEP or it was a little rich. It is possible to confirm the result that the $\mathrm{NO}_{\mathrm{x}}$ and $\mathrm{CO}$ emission characteristics using $\mathrm{SCV}$ are increased but that of $\mathrm{HC}$ and $\mathrm{CO}$ is reduced. These results are determined as a result of the effect of mixing that appears more clearly than the side of the air-resistance phenomena caused by swirl flow.

Figure $7 \mathrm{~b}$ shows the characteristics of $\mathrm{A} / \mathrm{F}$ in case of with $\mathrm{SCV}$ and without $\mathrm{SCR}$. The value of $\mathrm{A} / \mathrm{F}$ is constant by installation or non-installation of a SCV. The $\mathrm{NO}_{\mathrm{x}}$ characteristics in Figure 7c increase in the case of $\mathrm{SCV}$ installation. In addition, it was found that the case where the 2nd injection timing is ATDC 5CA is larger in case of injection timing TDC. The reason is that the swirl momentum has a great influence on the injection timing of ATDC 5CA. However, in the case of the smoke characteristics shown in Figure $7 d$, it shows an opposite tendency to that of $\mathrm{NO}_{x}$ characteristics. Under the influence of swirl moment the fuel and air should be sufficiently mixed because of the swirl (SCV). The HC and $\mathrm{CO}$ characteristics shown in Figure 7e,f show the trade-off relation between $\mathrm{HC}$ and $\mathrm{CO}$ as shown in the relation between $\mathrm{NO}_{x}$ and smoke.

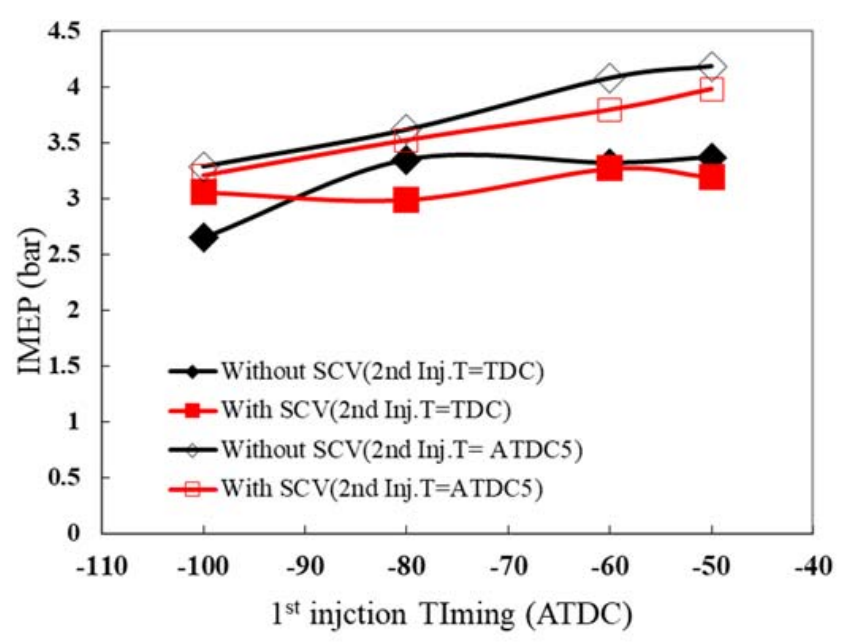

(a)

Figure 6. Cont. 


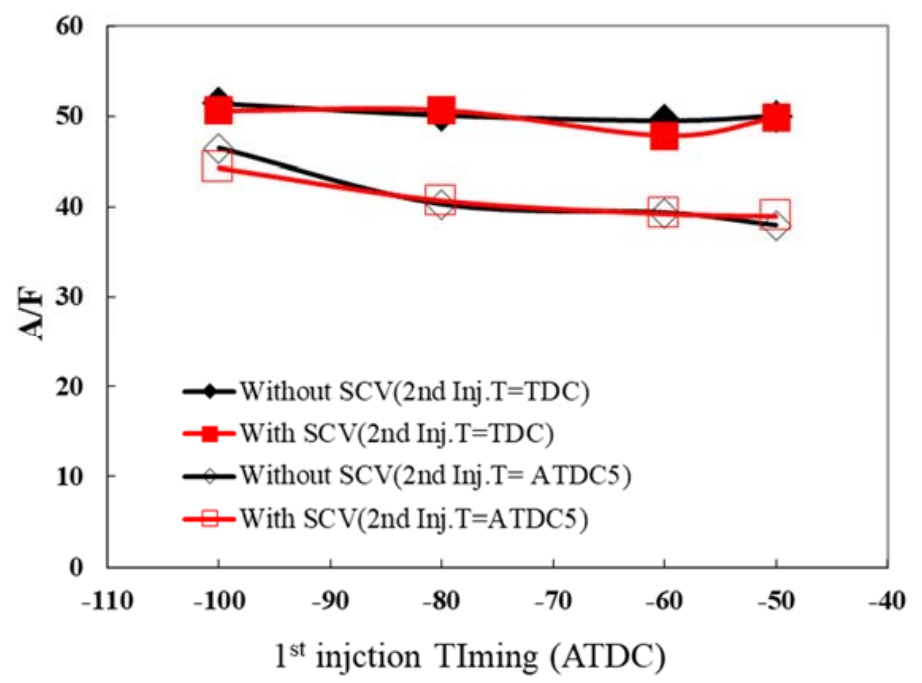

(b)

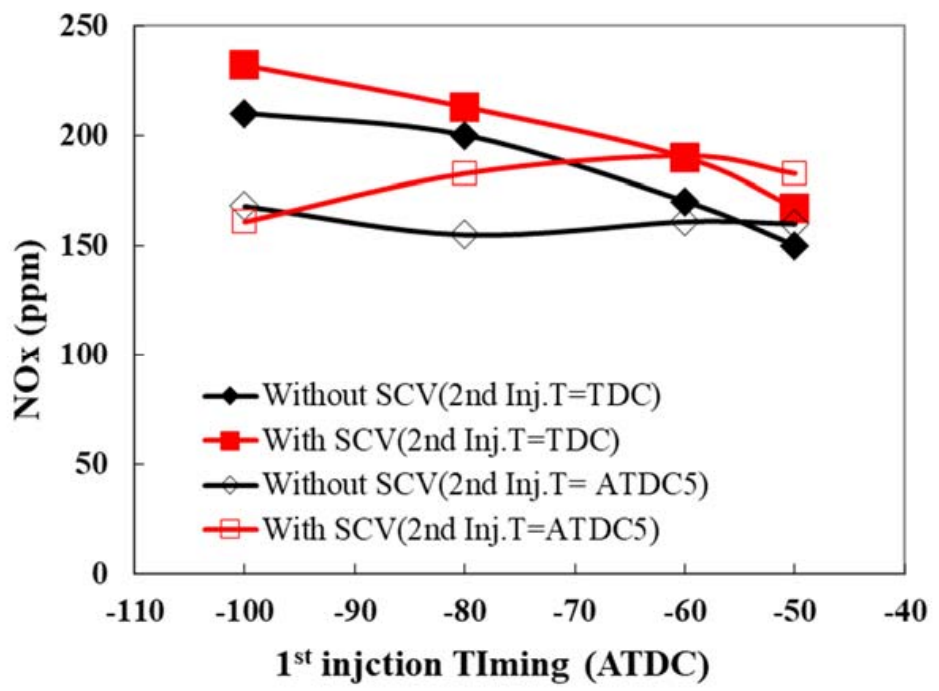

(c)

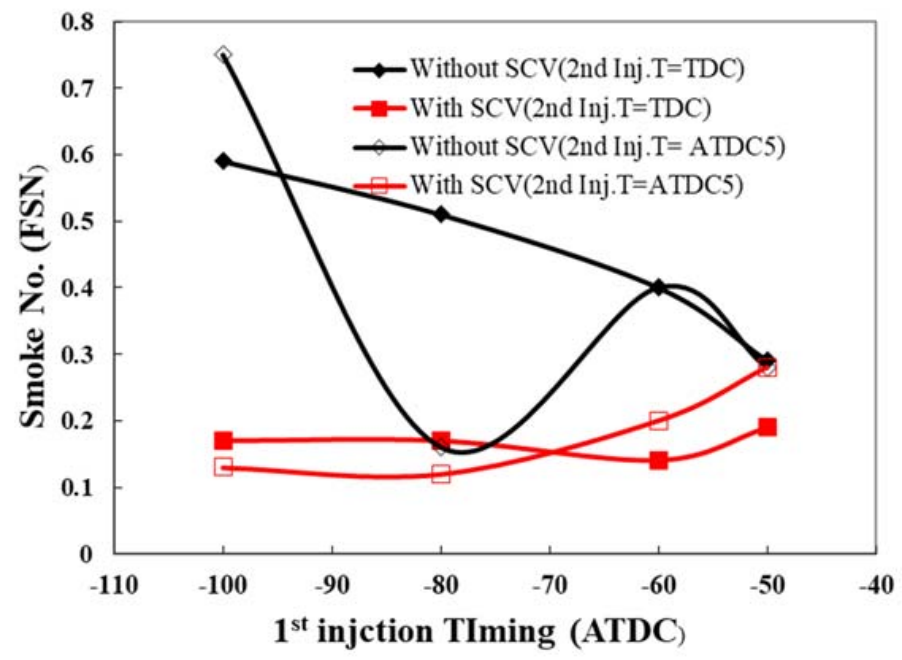

(d)

Figure 6. Cont. 


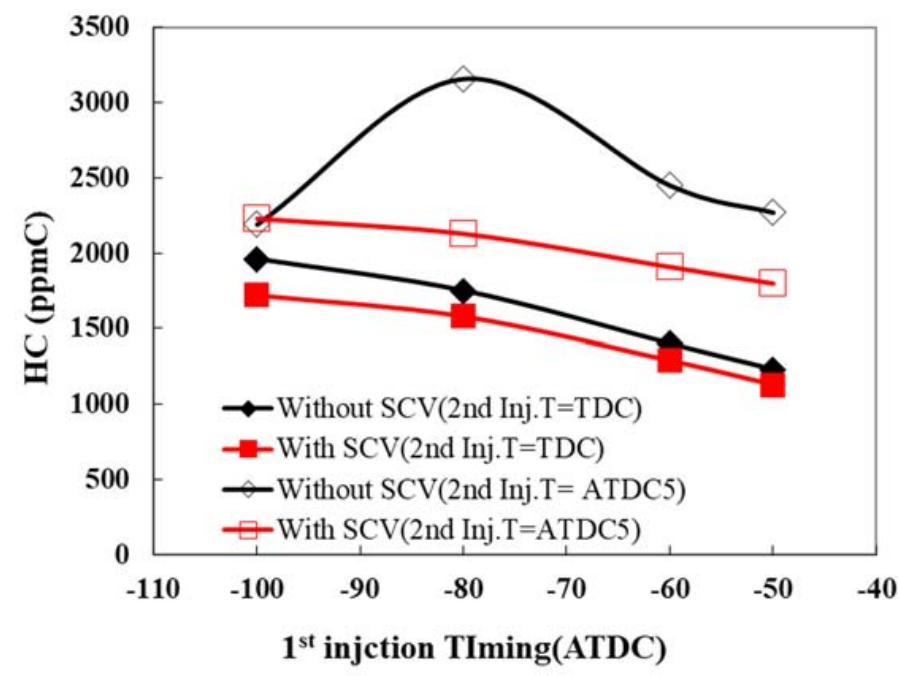

(e)

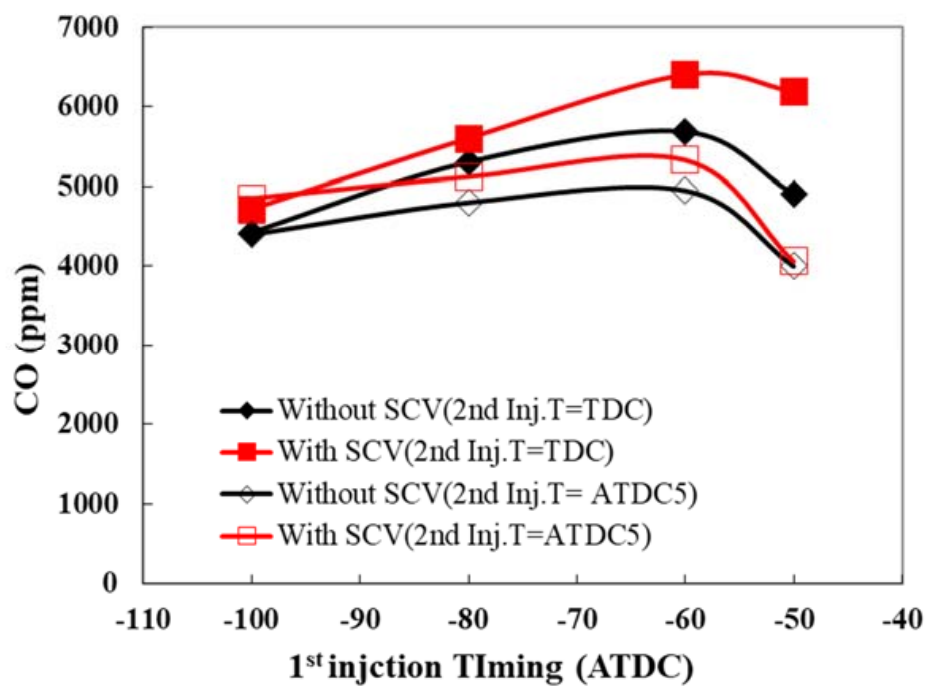

(f)

Figure 7. IMEP and emission performance applied SCV at the multi-injection mode $\left(20 \mathrm{~mm}^{3} /\right.$ stroke, 1400 rpm). (a) IMEP; (b) A/F; (c) NO ; (d) Smoke (FSN: Filter Smoke Number defined according ISO 10054); (e) HC; (f) CO.

The heat release rate was investigated in order to confirm these various performance results in more detail, and the experiment results are shown in Figures 8 and 9. The main phenomena in comparison with the results of the heat release rate are as follows:

(1) The ignition delay of the 1st injection according to the SCV

(2) Increase in the effect on the 2nd injection timing as the 1st injection time is advanced

As for the cause of the phenomenon as described above, it is considered to be the change of the swirl momentum in accordance with injected fuel amount (air-fuel ratio) and crank angle. The effect on the swirl flow is to promote the mixture but it caused an ignition delay owing to the rarefaction of the air-fuel ratio. This has been shown to have effects on the 2nd injection as the swirl momentum was aggravated and reduced according to the close TDC of the injection timing of the 1st injection. 


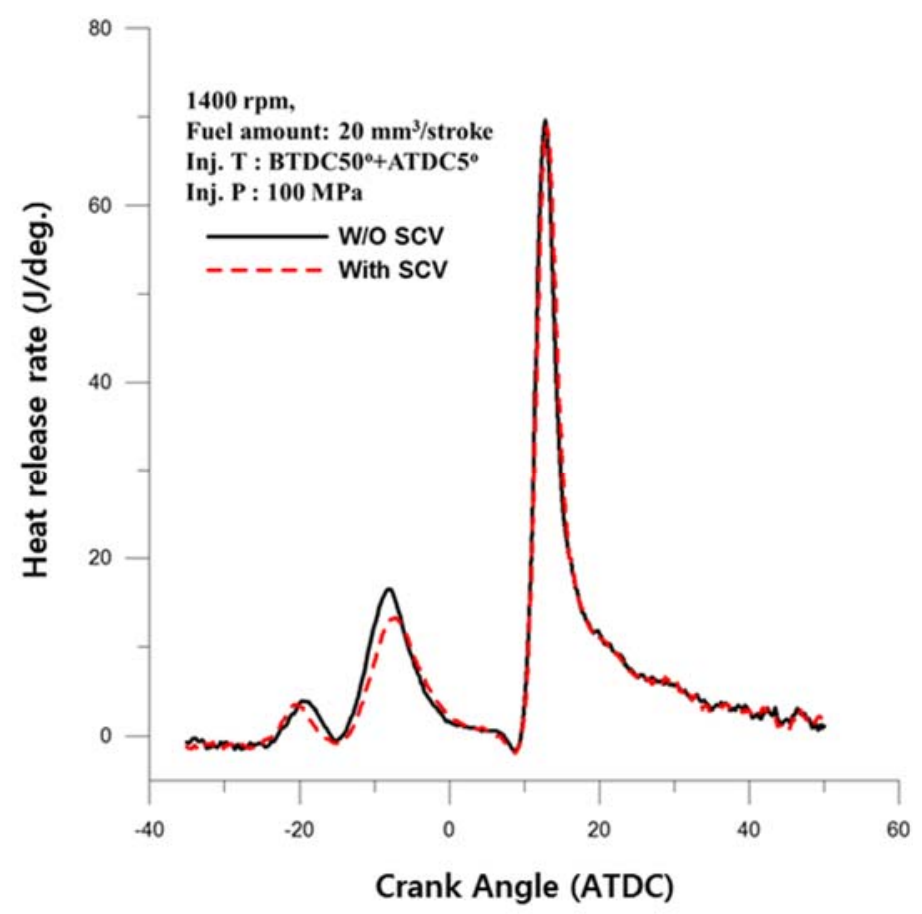

(a)

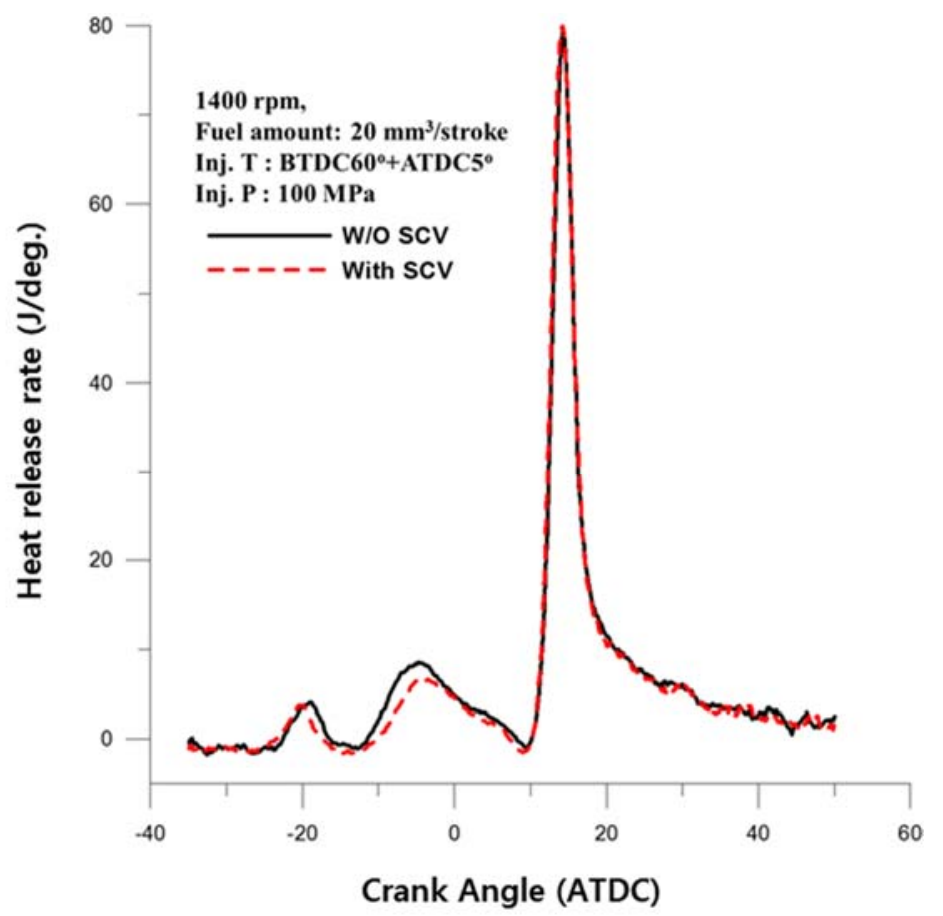

(b)

Figure 8. Cont. 


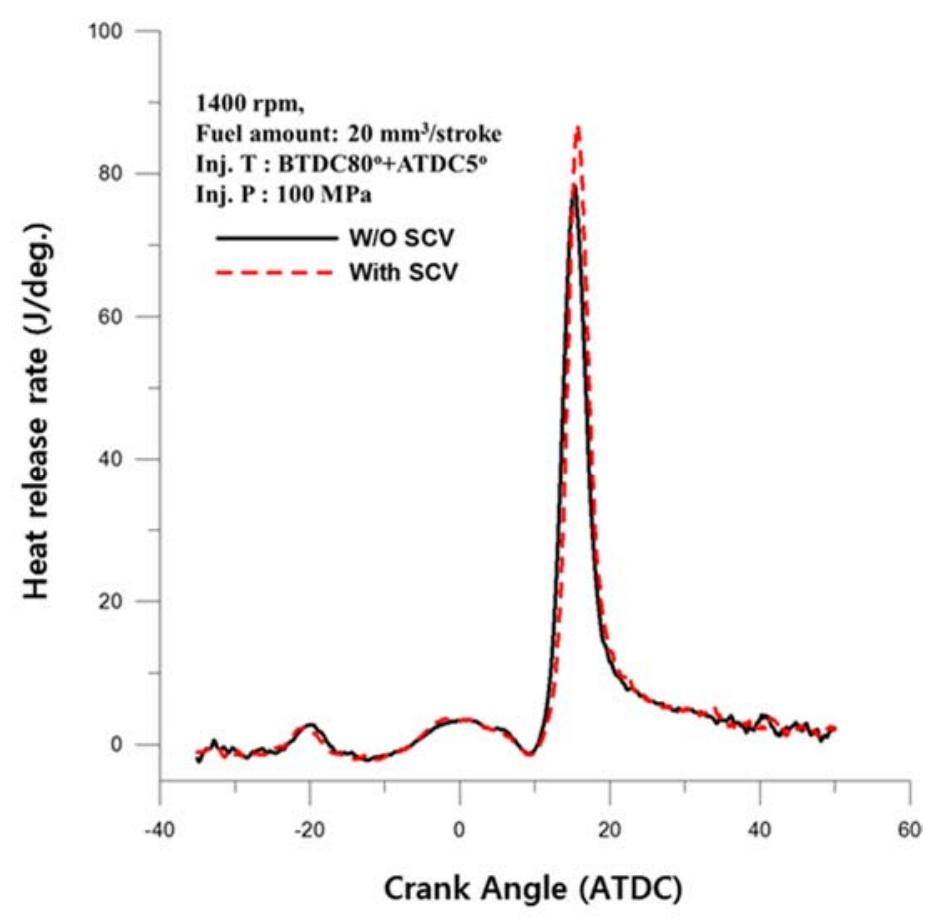

(c)

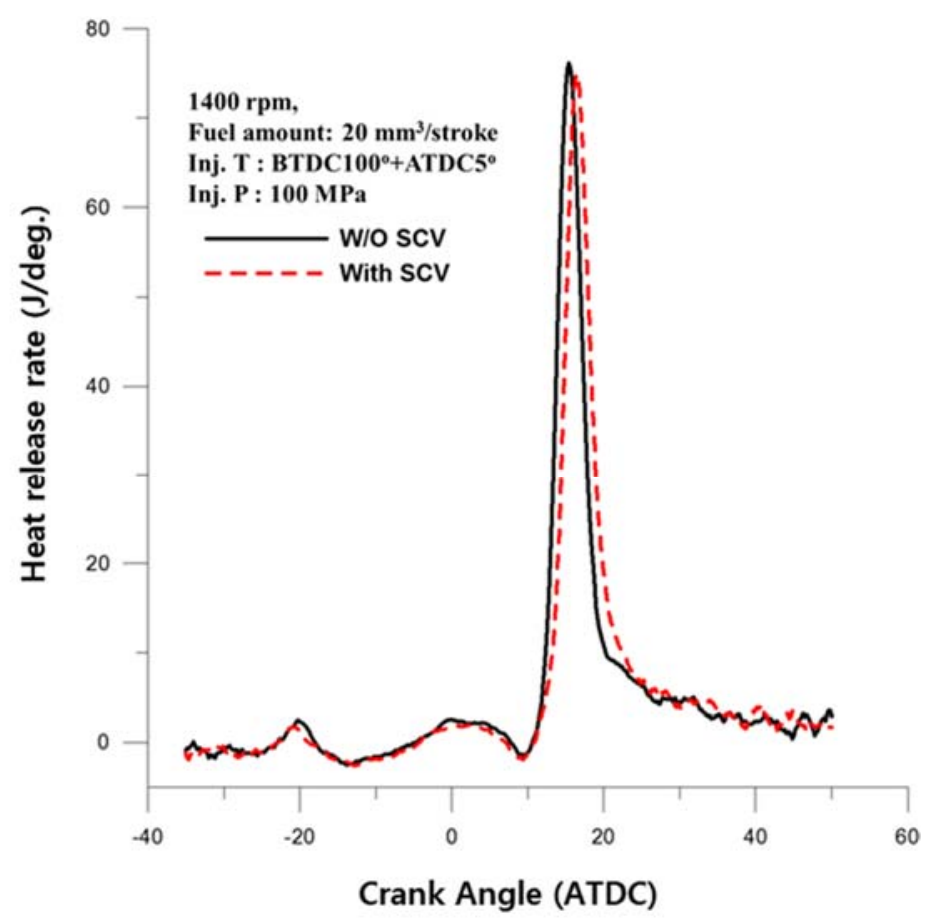

(d)

Figure 8. The effect on the SCV of the heat release rate during the 2 nd injection (1400 rpm, injection amount: $20 \mathrm{~mm}^{3} /$ stroke, 2nd injection timing: ATDC $5^{\circ}$ ). (a) Injection timing, 1st injection: BTDC $50^{\circ}, 2$ nd injection: ATDC $5^{\circ}$; (b) Injection timing, 1st injection: BTDC $60^{\circ}, 2$ nd injection: ATDC $5^{\circ}$; (c) Injection timing, 1st injection: BTDC $80^{\circ}$, 2nd injection: ATDC $5^{\circ}$; (d) Injection timing, 1st injection: BTDC $100^{\circ}$, 2nd injection: ATDC $5^{\circ}$. 


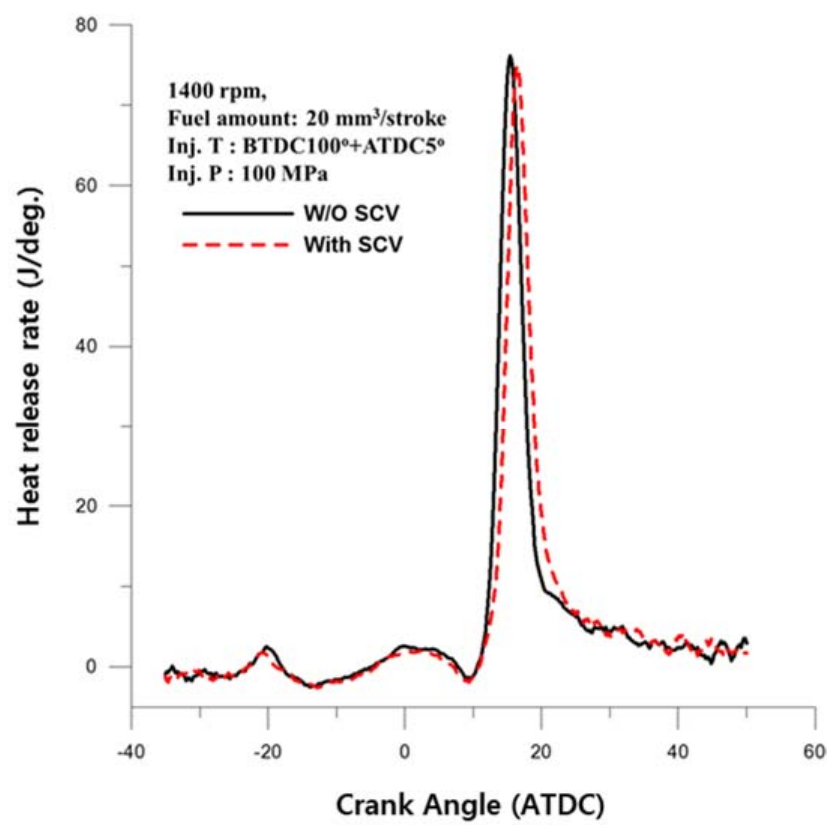

(a)

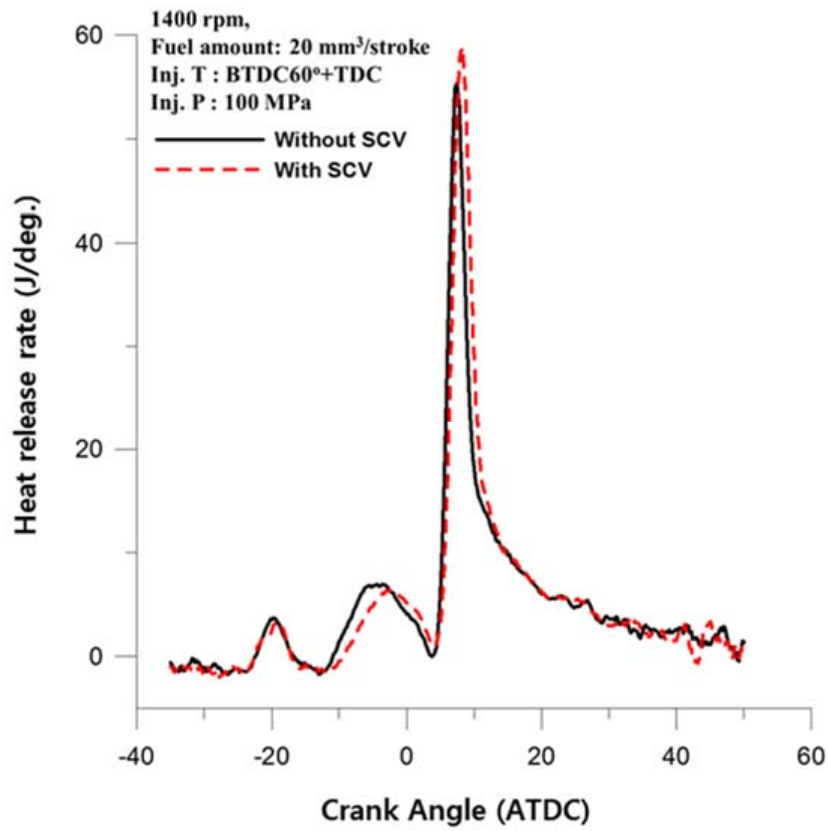

(b)

Figure 9. Cont. 


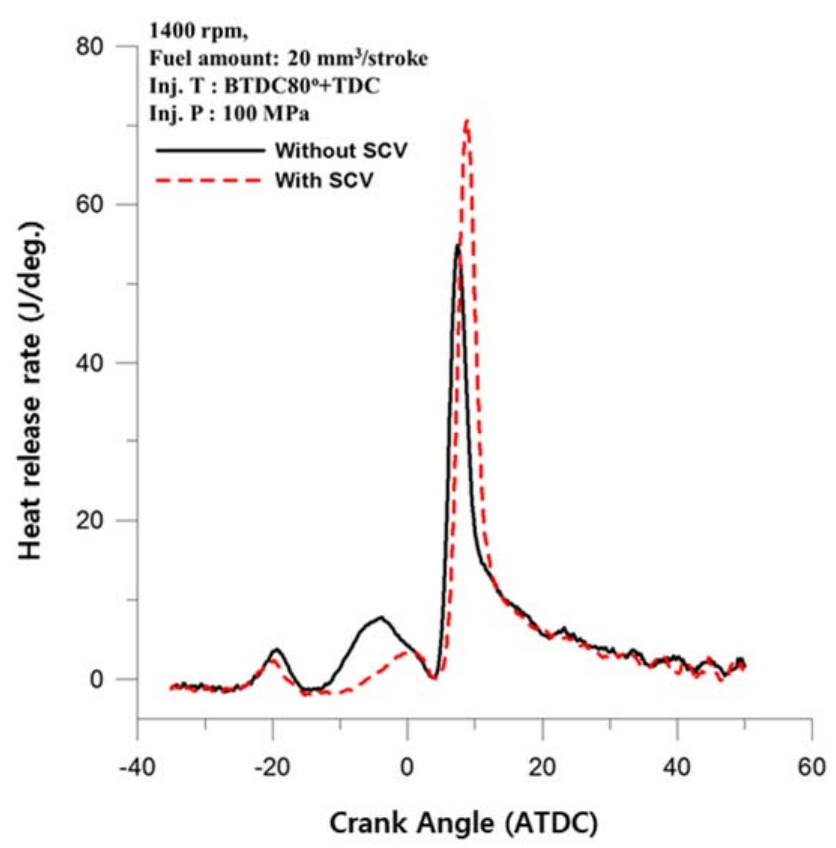

(c)

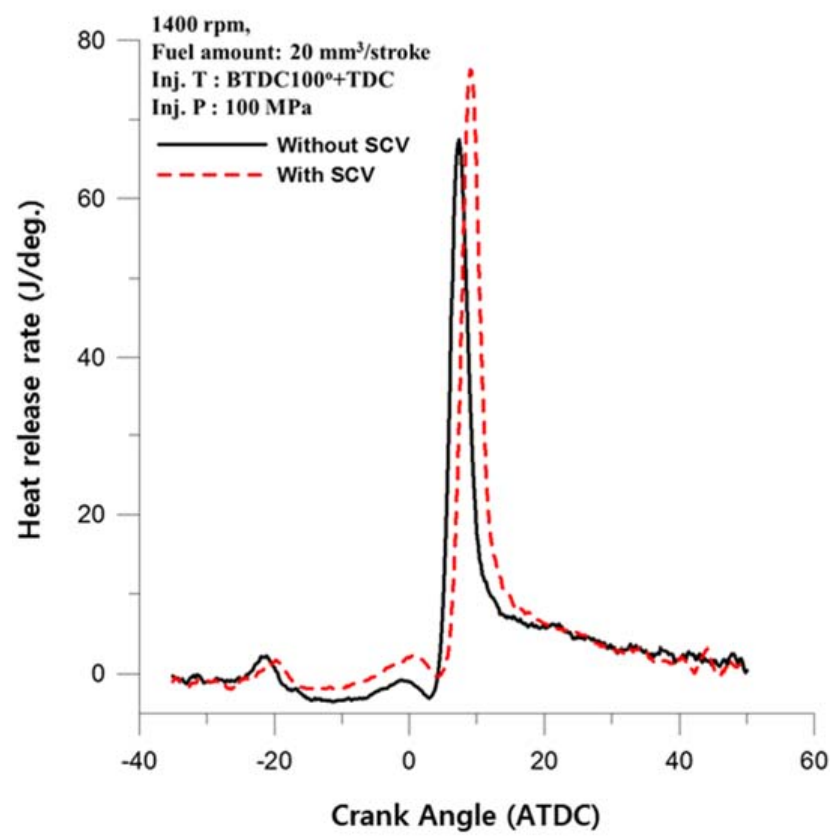

(d)

Figure 9. The effect on the SCV of the heat release rate during the 2nd injection (1400 rpm, injection amount: $20 \mathrm{~mm}^{3} /$ stroke, 2nd injection timing: TDC). (a) Injection timing, 1st injection: BTDC $50^{\circ}$, 2nd injection: TDC; (b) Injection timing, 1st injection: BTDC $60^{\circ}$, 2nd injection: TDC; (c) Injection timing, 1st injection: BTDC $80^{\circ}$, 2nd injection: TDC; (d) Injection timing, 1st injection: BTDC $100^{\circ}$, 2nd injection: TDC.

\subsection{Effect on the Exhaust Gas Recirculation}

The EGR technology reduces $\mathrm{NO}_{x}$ emissions by decreasing the combustion temperature during the diffusion combustion. Therefore, $\mathrm{NO}_{\mathrm{x}}$ reduction and the ignition control methodology are applied through the active use of EGR. However, an excess of EGR causes problems such as increase of the combustion instability and HC, CO emissions. Figures 10 and 11 show the evaluation of the effect 
of EGR under the conditions of compression ratio 17.8 and 15.0, $1400 \mathrm{rpm}$, injection amount 20, $30 \mathrm{~mm}^{3} /$ stroke, and the $30 \%$ of EGR rate. Figure 10 shows the various performance characteristics according to application of EGR as the compression ratio is 17.8. As shown in Figure 10a, the air-fuel ratio was less than half by using EGR. IMEP (Figure 10b) showed no large variation but it could be confirmed that the highest of IMEP is formed from about $10 \%$ of EGR rate. It could be applied to secure a $50 \mathrm{ppm}$ or less in both the level of injection amount 20 and $30 \mathrm{~mm}^{3} /$ stroke as the rate of EGR is about $10 \%$. Since the smoke tends to increase in accordance with the increase the EGR rate in the case of the diffusion combustion, the smoke measurements showed a very rich smoke emission (Figure 10c). On the other hand, when the injection amount of the split injection is $20 \mathrm{~mm}^{3} /$ stroke to apply the HCCI methodology, the smoke is not reduced in accordance with the increasing EGR rate. However, in case of $30 \mathrm{~mm}^{3} /$ stroke, it is dramatically increased according to the increase of the EGR rate. The HC and CO characteristics shown in Figure 10e,f increase in accordance with increasing EGR rate. The emission characteristics of smoke and $\mathrm{NO}_{\mathrm{x}}$ at the compression ratio 15 as shown in Figure 11 were similar to the phenomena of Figure 10, but the smoke emissions at the condition of the compression ratio 15 was reduced at the $30 \mathrm{~mm}^{3}$ /stroke in accordance with the increase of EGR rate as compared with Figure 10.

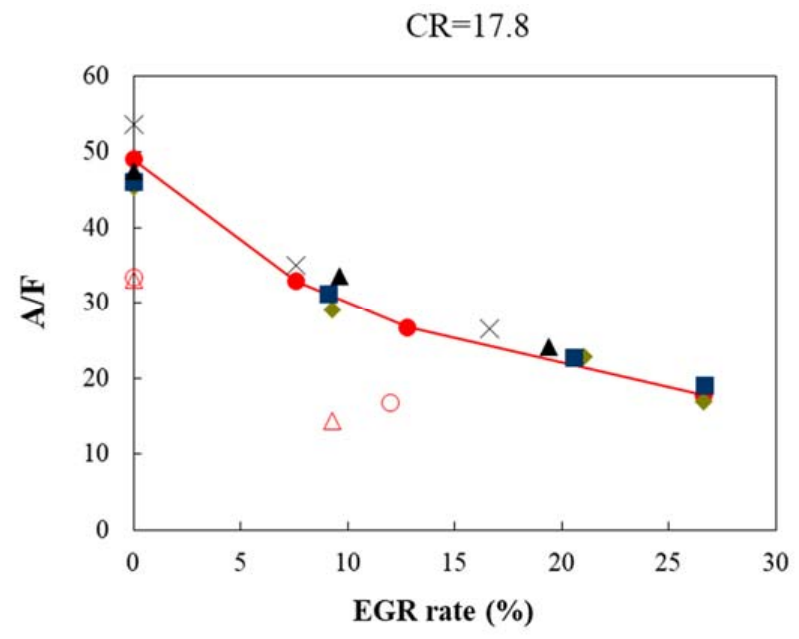

- Inj. $\mathrm{T}=\mathrm{b} 60+\mathrm{a} 5$, F. $A=20 \mathrm{~mm} 3 / \mathrm{st}$

- Inj. $\mathrm{T}=\mathrm{b} 80+\mathrm{a} 5$, F.A $=20 \mathrm{~mm} 3 / \mathrm{st}$

\ Inj. $\mathrm{T}=\mathrm{b} 60+\mathrm{a} 10$, F.A $=20 \mathrm{~mm} 3 / \mathrm{st}$

$\times$ Inj. $\mathrm{T}=\mathrm{b} 80+\mathrm{a} 10$, F.A $=20 \mathrm{~mm} 3 / \mathrm{st}$

- Inj. $\mathrm{T}=\mathrm{b} 80+\mathrm{a} 5$, F.A $=30 \mathrm{~mm} 3 / \mathrm{st}$

$\triangle$ Inj. $\mathrm{T}=\mathrm{b} 60+\mathrm{a} 5$, F. $A=30 \mathrm{~mm} 3 / \mathrm{st}$

$\longrightarrow$ Single(Inj. T=b10, F. $A=20 \mathrm{~mm} 3 / \mathrm{st}$ )

(a)

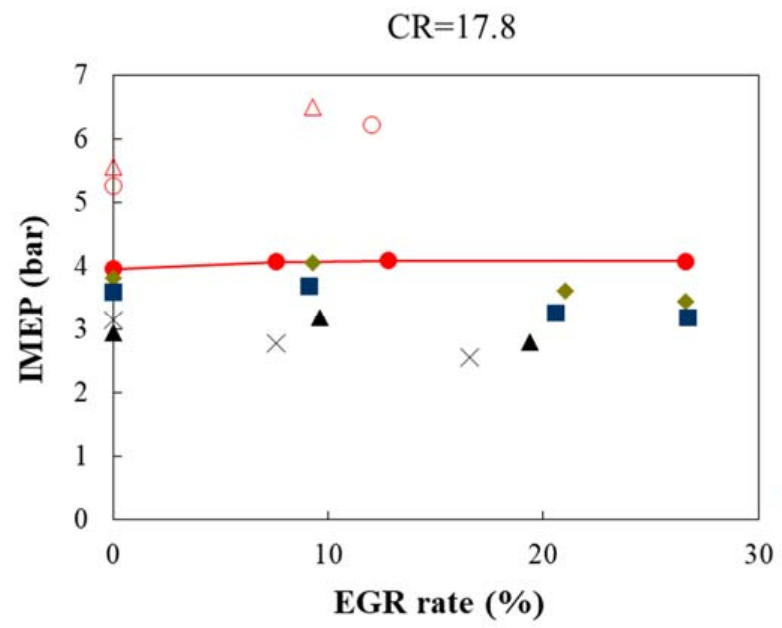

Inj. $\mathrm{T}=\mathrm{b} 60+\mathrm{a} 5$ F. $\mathrm{A}=20 \mathrm{~mm} 3 / \mathrm{st}$

Inj. $\mathrm{T}=\mathrm{b} 80+\mathrm{a} 5$, F. $\mathrm{A}=20 \mathrm{~mm} 3 / \mathrm{st}$

$\Delta$ Inj. $\mathrm{T}=\mathrm{b} 60+\mathrm{a} 10$, F. $\mathrm{A}=20 \mathrm{~mm} 3 / \mathrm{st}$

$\times$ Inj. $\mathrm{T}=\mathrm{b} 80+\mathrm{a} 10$, F. $\mathrm{A}=20 \mathrm{~mm} 3 / \mathrm{st}$

- Inj. $\mathrm{T}=\mathrm{b} 80+\mathrm{a} 5$, F. $\mathrm{A}=30 \mathrm{~mm} 3 / \mathrm{st}$

$\triangle$ Inj. $\mathrm{T}=\mathrm{b} 60+\mathrm{a} 5$, F. $\mathrm{A}=30 \mathrm{~mm} 3 / \mathrm{st}$

- Single(Inj. T=bl0, F.A $=20 \mathrm{~mm} 3 / \mathrm{st}$ )

(b)

Figure 10. Cont. 


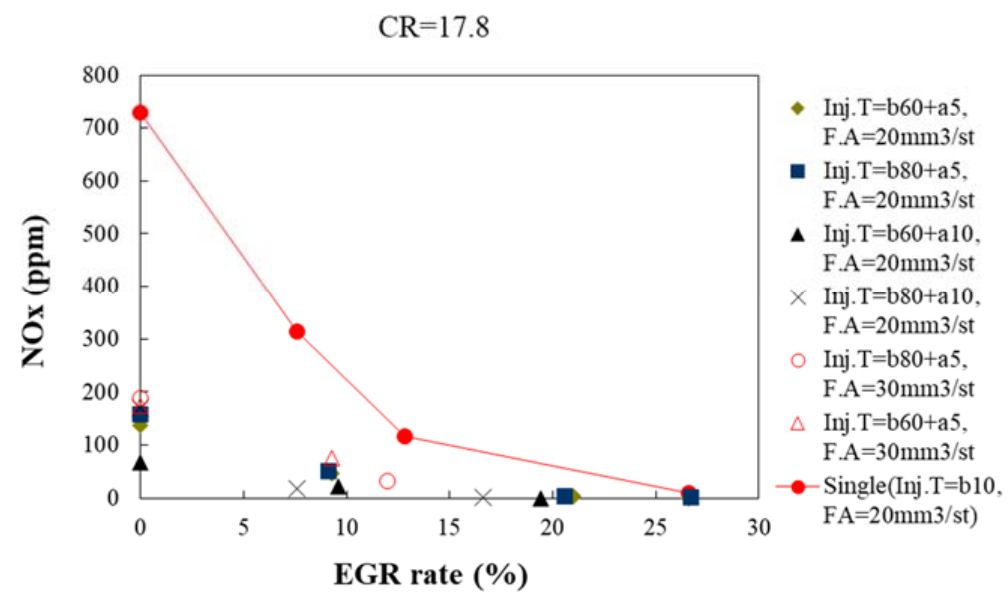

(c)

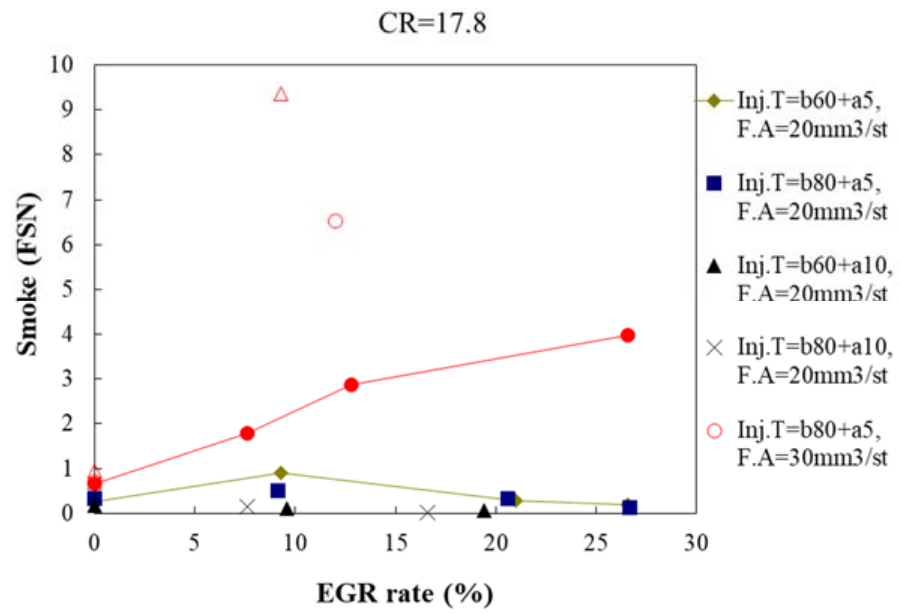

(d)

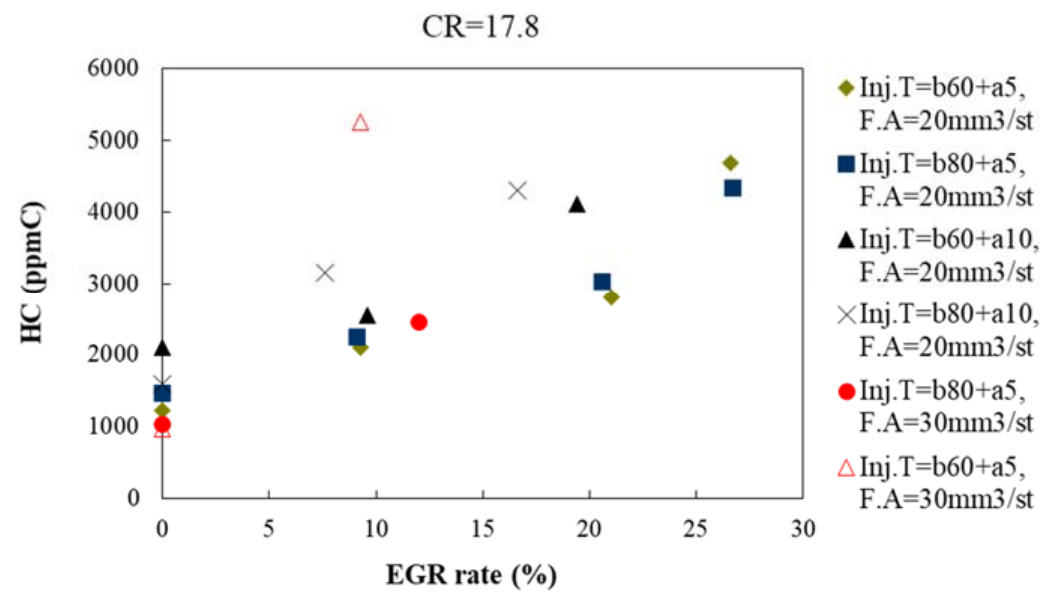

(e)

Figure 10. Cont. 


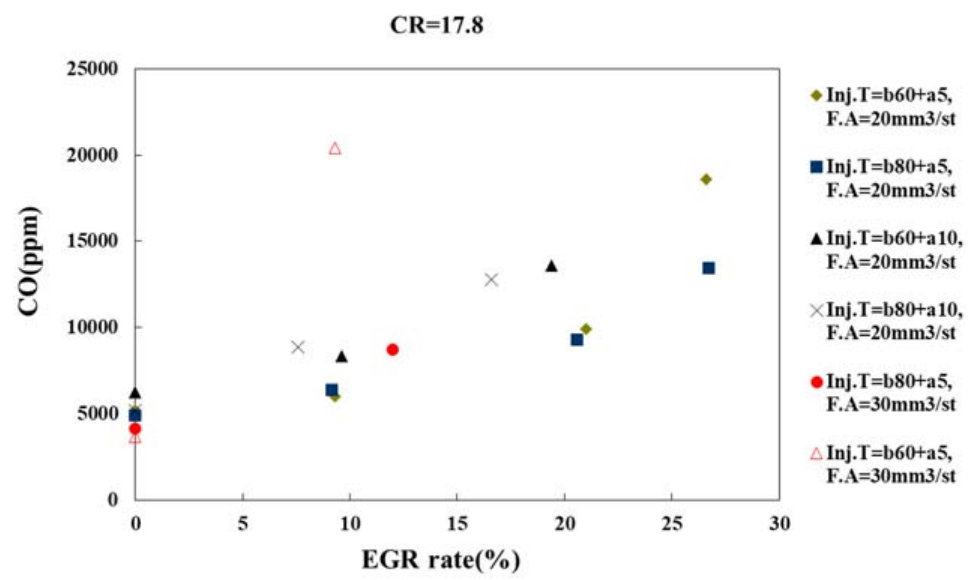

(f)

Figure 10. Performance characteristics of IMEP and emission applied to EGR (compression ratio: 17.8, $1400 \mathrm{rpm}$, injection amount: 20, $30 \mathrm{~mm}^{3} /$ stroke). (a) Variation of air-fuel ratio according to EGR; (b) Variation of IMEP according to EGR; (c) Variation of $\mathrm{NO}_{\mathrm{x}}$ according to EGR; (d) Variation of Smoke according to EGR; (e) Variation of HC according to EGR; (f) Variation of CO according to EGR.

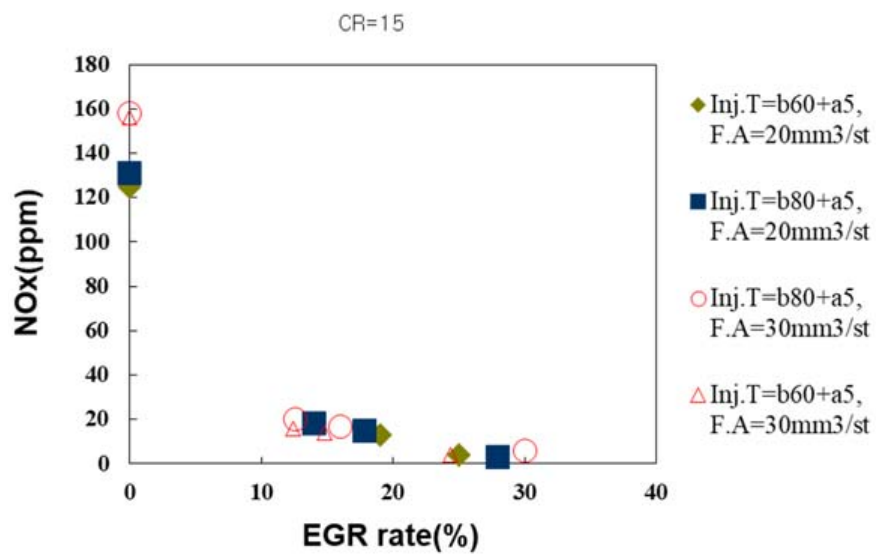

(a)

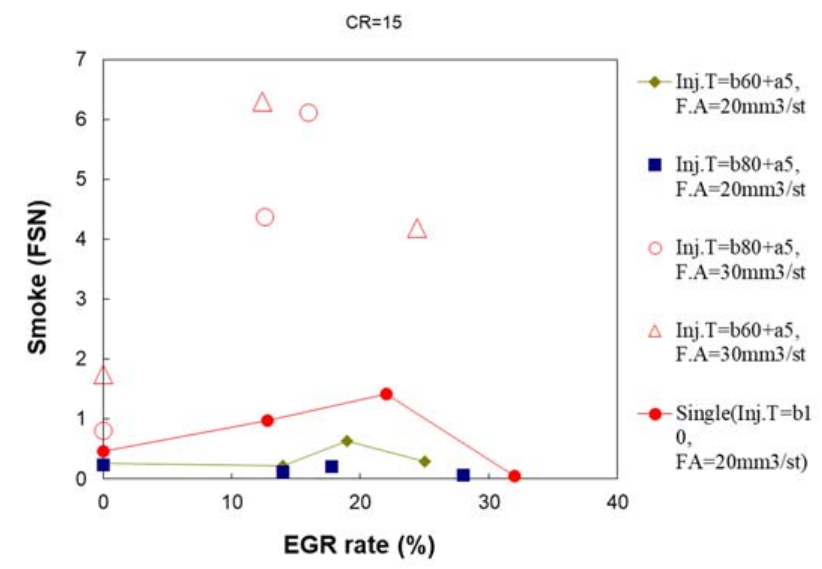

(b)

Figure 11. Performance characteristics of IMEP and emission applied to EGR (compression ratio: 15.0, $1400 \mathrm{rpm}$, injection amount: 20, $30 \mathrm{~mm}^{3}$ /stroke). (a) $\mathrm{NO}_{\mathrm{x}}$ according to EGR rate; (b) Smoke according to EGR rate. 


\subsection{Effect on the Charging Pressure}

In case where the conditions are split injection, $1400 \mathrm{rpm}$, injection pressure $100 \mathrm{MPa}$, compression ratio 17.8 and 20,30, $40 \mathrm{~mm}^{3}$ /stroke injection amount, Figures 12 and 13 show on the emission characteristics of $\mathrm{NO}_{x}$ and smoke in accordance with the charging pressure changes of 1000, 1200, 1400 mbar.

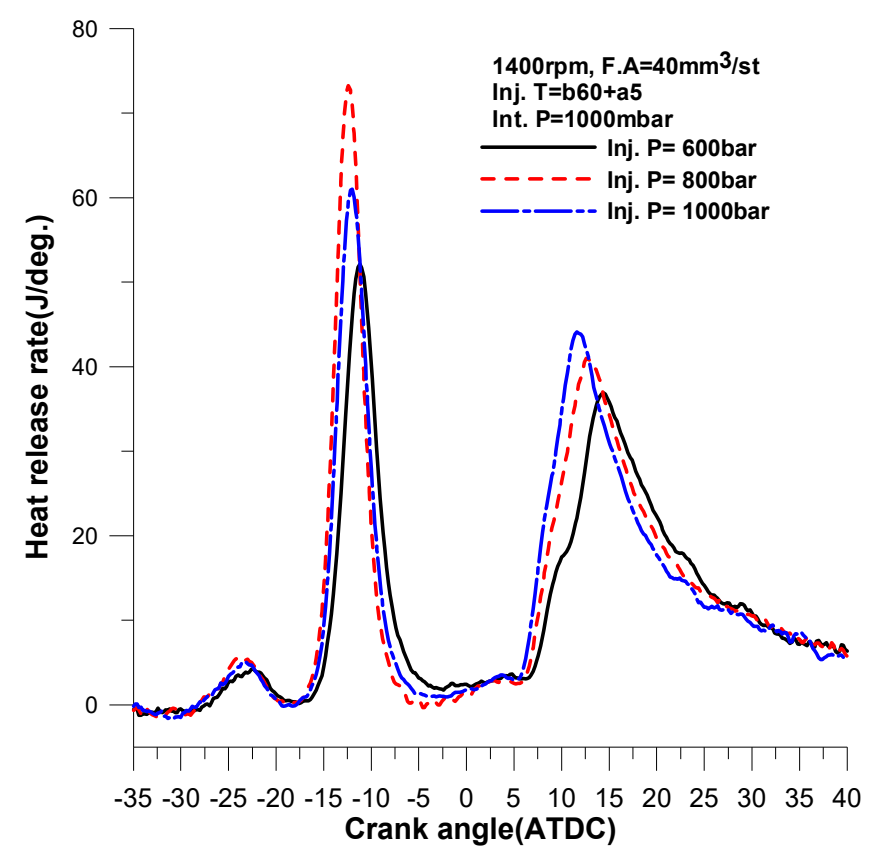

(a)

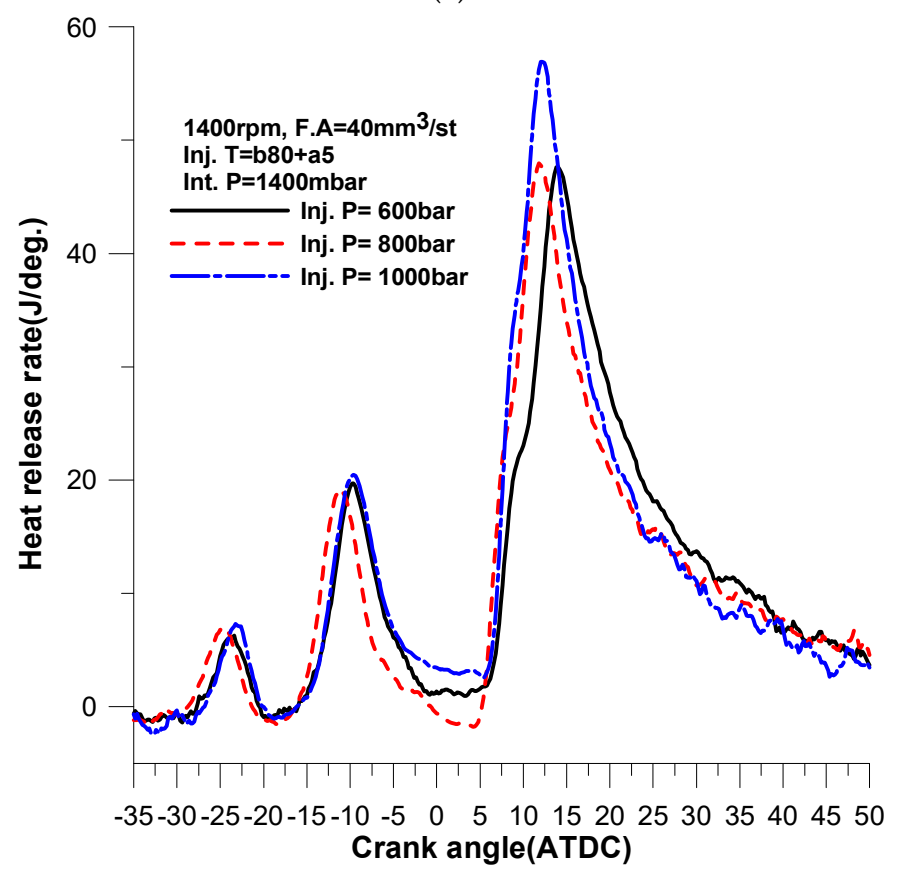

(b)

Figure 12. Characteristics of the heat release rate in accordance with change the boost pressure. (a) Injection timing, 1st injection BTDC 60CA 2nd injection ATDC 5CA, charging pressure $=1000$ mbar; (b) Injection timing, 1st injection BTDC 60CA 2nd injection ATDC 5CA, charging pressure $=1400$ mbar. 
$C / R=17.8,1400 \mathrm{rmm}$, inj. $P=1000 \mathrm{bar}$

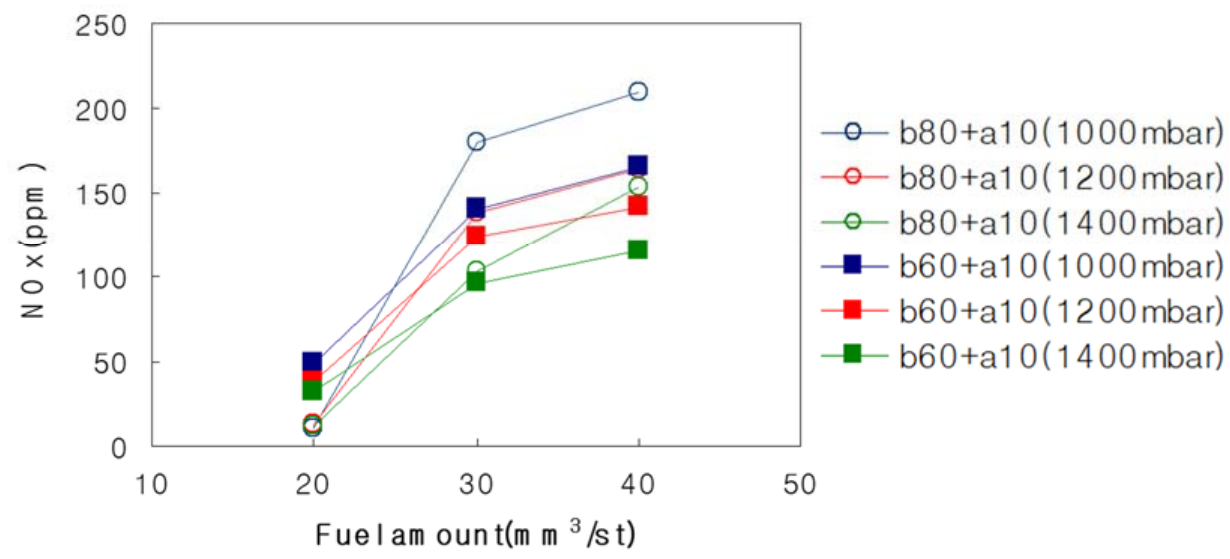

(a)

$C / R=17.8,1400 \mathrm{rpm}$, inj. $P=1000 \mathrm{bar}$

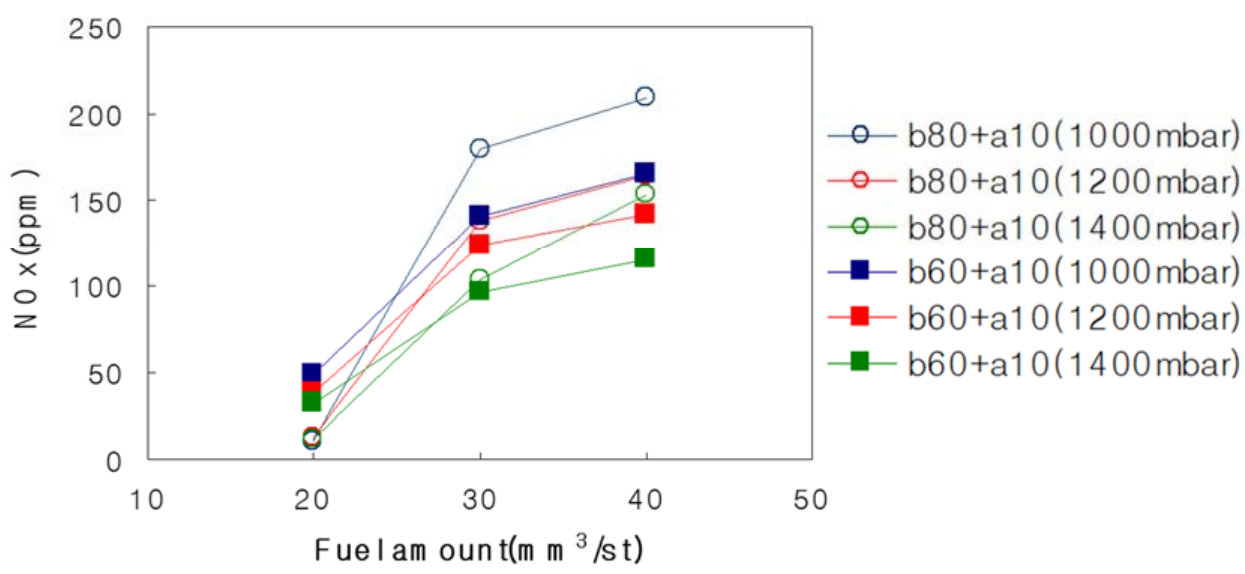

(b)

$C / R=17.8,1400 \mathrm{rpm}$, inj. $P=1000 \mathrm{bar}$

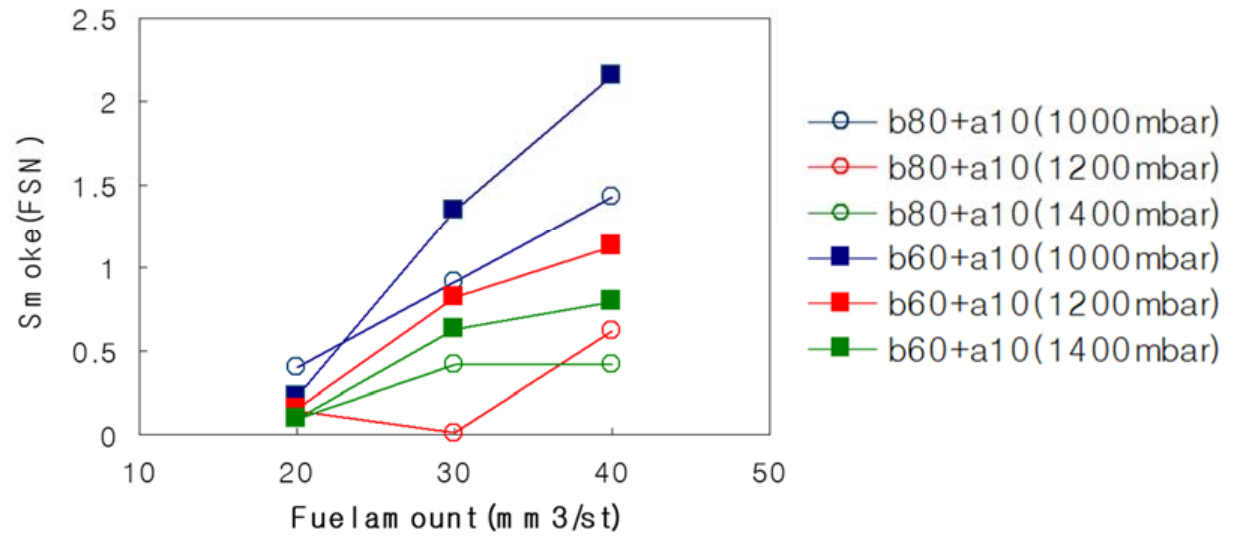

(c)

Figure 13. Cont. 


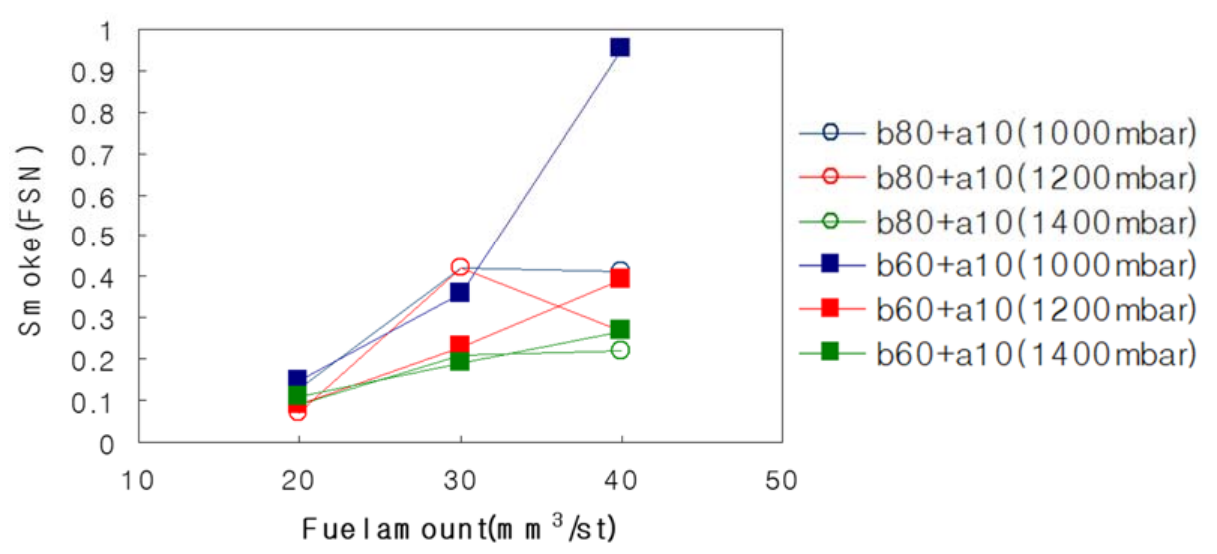

(d)

Figure 13. Characteristics of the exhaust emission in accordance with change the boost pressure. (a) Characteristics of $\mathrm{NO}_{x}$ emission (injection timing, 1st inj.: BTDC 80 , 2nd inj.: $\operatorname{ATDC} 5^{\circ}$ ); (b) Characteristics of $\mathrm{NO}_{x}$ emission (injection timing, 1st inj.: $\mathrm{BTDC} 80^{\circ}$, 2nd inj.: $\mathrm{ATDC} 10^{\circ}$ );

(c) Characteristics of smoke emission (injection timing, 1st inj.: BTDC $80^{\circ}$, 2nd inj.: ATDC $5^{\circ}$ );

(d) Characteristics of smoke emission (injection timing, 1st inj.: BTDC $80^{\circ}$, 2nd inj.: ATDC $10^{\circ}$ ).

Figure 12 shows the heat release rate in accordance with the change of the charging pressure. Because of the heat release rate, the increase of the charging pressure shows that both the 1st injection and the ignition or combustion of the 2nd injection are accelerated. In this case, it is considered that the smoke is reduced even if the ignition delay is shortened because the fuel mixture is generated efficiently by the proportion to charging pressure. In particular, the influence of the 2nd injection on the combustion rate pattern seems to be larger, which means that the fuel injected in the first stage is ignited at the crank angle at the ignition conditions is formed after the fuel injection. However, it is estimated that the 2nd injected fuel is more affected by ignition after the fuel is injected.

From these results, it was found that the increase of boost pressure decreases the emissions of $\mathrm{NO}_{\mathrm{x}}$ and smoke due to dilution of the mixture. As the HCCI combustion conditions are an injection timing such as 1st injection BTDC $80^{\circ}$ and 2nd injection ATDC $10^{\circ}$, the smoke emissions are basically reduced. On the other hand, the reduction rates with increasing boost pressure indicated the characteristics of the partial-HCCI have slowed as compared to the conditions of 1st injection BTDC $80^{\circ}$, 2nd injection ATDC $5^{\circ}$. Therefore, it is possible to lower the boost pressure rate as the excellent premixing rate in terms of exhaust gas is a result of the injection angle. It could be necessary to strengthen the dilution with a relatively higher boost pressure under the conditions of partial-HCCI in the case excellent power performance is desired.

\section{Conclusions}

A multi-injection method with the HCCI combustion mode using a commercial engine was investigated in this paper. As the 2nd stage injection system was applied to this study rather than the implementation of a complete HCCI combustion, there is a tendency towards partial premixed diesel combustion, and the effects of various combustion factors for improving combustion and exhaust performance were discussed. The conclusions can be summarized as follows:

(1) Considering the characteristics of injection timing, exhaust gas and IMEP, the appropriate 1st injection timing has been determined to be BTDC $80-60^{\circ}$ and a 2nd injection timing close to ATDC $10^{\circ}$ has been determined to be reasonable. The results from the characteristics stated above were considered for ways to improve performance. The way to improve the performance is a 
delay such that the ignition of first fuel injection is close to TDC so that the combustion is active. The second fuel injection effect is to promote the premixing rate by possibly delaying the ignition.

(2) The main phenomena in comparison with the results of the heat release rate are as follows:

(a) The ignition delay of the 1st injection according to the SCV

(b) Increase in the effect on the 2nd injection timing as the 1st injection time is advanced

(3) The air-fuel ratio was evaluated at less than half by using EGR. IMEP showed no large variation but it could be confirmed that the highest IMEP is formed at about $10 \%$ of the EGR rate. As the injection amount of the split injection is $20 \mathrm{~mm}^{3}$ / stroke to apply the HCCI methodology, the smoke is not reduced in accordance with the increasing EGR rate, however, in case of $30 \mathrm{~mm}^{3}$ /stroke, it is dramatically increased according to the increase of the EGR rate.

(4) It is possible to lower the boost pressure rate as the best premixing rate in terms of exhaust gas depends on the injection angle. It could be necessary to strengthen the dilution with a relatively higher boost pressure at the condition of the partial-HCCI for the excellent power performance case.

Acknowledgments: This research was supported by Development of key fusion technology for Industry-academia-research cooperation cluster support project.

Author Contributions: Jaewoo Chung conceived and designed the experiments; Jaewoo Chung performed the experiments; Changhee Lee and Kihyung Lee analyzed the data; Jaewoo Chung contributed reagents/materials/analysis tools; Changhee Lee wrote the paper.

Conflicts of Interest: The authors declare no conflict of interest.

\section{References}

1. Simescu, S.; Ryan, T.; Neely, G.; Matheaus, A. Partial Pre-Mixed Combustion with Cooled and Uncooled EGR in a Heavy-Duty Diesel Engine. SAE Tech. Pap. 2002. [CrossRef]

2. Yokota, H.; Kudo, Y.; Nakajima, H.; Kakegawa, T. A New Concept for Low Emission Diesel Combustion. SAE Tech. Pap. 1997. [CrossRef]

3. Akagawa, H.; Miyamoto, T.; Harada, A.; Sasaki, S. Approaches to Solve Problems of the Premixed Lean Diesel Combustion. SAE Tech. Pap. 1999. [CrossRef]

4. Kimura, S.; Aoki, O.; Ogawa, H.; Muranaka, S. New Combustion Concept for Ultra-Clean and High-Efficiency Small DI Diesel Engines. SAE Tech. Pap. 1999. [CrossRef]

5. Hasegawa, R.; Yanagihara, H. HCCI Combustion in DI Diesel Engine. SAE Tech. Pap. 2003. [CrossRef]

6. Kwon, O.Y.; Ryu, J.D.; Lee, K.H.; Lee, C.S. Flame and Combustion Characteristics of D.I HCCI Engine using a Visualization Engine. Trans. KSAE 2002, 10, 100-107.

7. Song, B.H.; Kim, D.K.; Cho, N.H. A Cycle Simulation Method for an HCCI Engine using Detailed Chemical Kinetics. Trans. KSAE 2003, 11, 51-58.

8. Onishi, S.; Jo, S.; Shoda, K.; Jo, P. Active Thermo-Atmosphere Combustion (ATAC)—A New Combustion Process for Internal Combustion Engines. SAE Tech. Pap. 1979. [CrossRef]

9. Najt, P.; Foster, D. Compression-Ignited Homogeneous Charge Combustion. SAE Tech. Pap. 1983. [CrossRef]

10. Takeda, Y.; Keiichi, N.; Keiichi, N. Emission Characteristics of Premixed Lean Diesel Combustion with Extremely Early Staged Fuel Injection. SAE Tech. Pap. 1996. [CrossRef]

11. Aoyama, T.; Hattori, Y.; Mizuta, J.; Sato, Y. An Experimental Study on Premixed-Charge Compression Ignition Gasoline Engine. SAE Tech. Pap. 1996. [CrossRef]

12. Ishibashi, Y.; Asai, M. Improving the Exhaust Emissions of Two-Stroke Engines by Applying the Activated Radical Combustion. SAE Tech. Pap. 1996. [CrossRef]

13. Oakley, A.; Zhao, H.; Ladommatos, N.; Ma, T. Experimental Studies on Controlled Auto-ignition (CAI) Combustion of Gasoline in a 4-Stroke Engine. SAE Tech. Pap. 2001. [CrossRef]

14. Lee, C.H.; Lee, K.H. An experimental study of the combustion characteristics in SCCI and CAI based on direct-injection gasoline engine. Exp. Therm. Fluid Sci. 2007, 31, 1121-1132. [CrossRef] 
15. Lee, K.; Lee, C. An Experimental Study of the Extent of the Operating Region and Emission Characteristics of Stratified Combustion Using the Controlled Autoignition Method. Energy Fuels 2006, 20, 1862-1869. [CrossRef]

16. Lee, C.H.; Lee, K.H. An Experimental Study on the Combustion and Emission Characteristics of a Stratified Charge Compression Ignition (SCCI) Engine. Energy Fuels 2007, 21, 1901-1907. [CrossRef]

17. Mauya, R.; Agawal, A. Experimental study of combustion and emission characteristics of ethanol compression ignition (HCCI) combustion engine. Appl. Energy 2011, 88, 1169-1180. [CrossRef]

18. Kim, D.S.; Kim, M.Y.; Lee, C.S. Effect of premixed gasoline fuel on the combustion characteristics of compression ignition engine. Energy Fuels 2004, 18, 1213-1219. [CrossRef]

19. Lu, X.; Han, D.; Huang, Z. Fuel design and management for the control of advanced compression-ignition modes. Prog. Energy Combust. Sci. 2011, 37, 741-783. [CrossRef]

20. Charanlambides, A.G.; Sahu, S.; Hardalupas, Y.; Taylor, A.M.K.P.; Urata, Y. Evaluation of homogeneous charge compression ignition (HCCI) auto ignition development through chemiluminescence imaging and proper orthogonal decomposition. Appl. Energy 2018, 210, 288-302. [CrossRef]

21. Chung, J.W.; Kang, J.H.; Kim, B.S.; Kang, W.; Kim, H.C. A Study on the Diesel DI-HCCI Combustion Characteristics using 2-stage Injection Method. Trans. KSAE 2004, 12, 66-73.

(c) 2017 by the authors. Licensee MDPI, Basel, Switzerland. This article is an open access article distributed under the terms and conditions of the Creative Commons Attribution (CC BY) license (http:/ / creativecommons.org/licenses/by/4.0/). 